\title{
Las elecciones de diputados provinciales en el franquismo: la Diputación provincial de Valladolid (1949-1979)
}

\author{
Jesús María Palomares Ibáñez
}

Sumario: INTRODUCCIÓN. UN PROCESO REGLAMENTADO AL DETALLE. LAS PRIMERAS ELECCIONES PROVINCIALES DE LA DEMOCRACIA ORGÁNICA (1949). COMIENZA LA NUEVA CORPORACIÓN PROVINCIAL. LA PRIMERA RENOVACIÓN TRIENAL DE LA DIPUTACIÓN. LAS ELECCIONES DE 1955. LA NUEVA DIPUTACIÓN DE 1958. LAS ELECCIONES DE 1961. LAS ELECCIONES PROVINCIALES DEL AÑO 1964. LAS ELECCIONES DE 1967. CON UN AÑO DE RETRASO: LAS ELECCIONES PROVINCIALES DE 1971. LAS ÚLTIMAS ELECCIONES DE DIPUTADOS PROVINCIALES DEL FRANQUISMO (1974). LA RENOVACIÓN PARCIAL DE 1976. ANEXO.

\section{INTRODUCCIÓN}

Al igual que el Ayuntamiento capitalino la Diputación vivió subordinada de plano a la trama impuesta por el régimen franquista, sujeta por un férreo control y sumisión que afectó a las instituciones de la administración local. Desde los inicios de la guerra civil debió acomodarse a la nueva situación, enseguida plasmada en la composición de las comisiones gestoras ${ }^{1}$, mientras que órdenes posteriores establecían el número de gestores, nombramiento, competencias y dependencia del gobernador civil. Durante el periodo inmediato de posguerra, la corporación provincial experimentó dos renovaciones de sus gestoras en el último mes de 1939 y 1943, respectivamente. En ambos casos, por nombramiento del gobernador entre personas de su confianza y, no hace falta recordarlo, afectas al régimen, según consta en los informes que remite al subsecretario de Gobernación. El segundo de los cambios tuvo efecto en la sesión del 16 de diciembre de 1943. De momento, permaneció el mismo presidente de la anterior Eusebio Rodríguez Fernández-Vila. Le acompañan cinco nuevos gestores: Víctor Gómez Ayllón, Emiliano Berzosa, Antolín de Santiago, Eusebio Alonso Pérez-Hickman y Carlos Sanz Alonso ${ }^{2}$. Pocos meses después, en la sesión extraordinaria que preside el gobernador Tomás Romojaro, asumirá la presi-

\footnotetext{
1 Decreto de la Junta Técnica del Estado 5 de octubre de 1936.

2 Sesión 16.12.43, Boletín Oficial de la Provincia de Valladolid (BOPVa) 22.01.44, 4.
} 
dencia Juan Represa ${ }^{3}$, sin haber sido previamente miembro de la comisión gestora provincial.

En 1945 el gobierno del así titulado Nuevo Estado promulga la Ley de Bases de Régimen Local ${ }^{4}$, auténtico corsé de los ayuntamientos y diputaciones durante el franquismo. Conforme define esta norma a la Provincia y la Diputación provincial, aquélla reviste la condición de agrupación de municipios y división territorial «de carácter unitario para el ejercicio de la competencia del Gobierno central». Integraban la corporación provincial el presidente (nombrado por el ministro de la Gobernación) y los diputados provinciales, a razón de uno por cada partido judicial (y mandato de seis años renovados por mitad cada tres ${ }^{5}$ ).

Con todo, será en 1949 cuando el tiempo de las Comisiones Gestoras cederá paso a los Diputados. Con ello se recobra el nombre anterior, al tiempo que se renueva la composición y número del organismo ${ }^{6}$. Desde ahora, los diputados serán elegidos mediante el sistema orgánico o corporativo, entre los municipios de los partidos judiciales y las entidades reconocidas oficialmente tras inscribirse -requisito indispensable para participar en el proceso electoral- en el registro especial abierto a tales efectos en el Gobierno Civil. Aquí situamos nuestro análisis circunscrito al proceso electoral que inaugura la convocatoria abierta en febrero de 1949.

En febrero del mismo año, quedaron constituidos los ayuntamientos votados en las primeras elecciones orgánicas del franquismo. A renglón seguido, arrancó el calendario electoral para renovar en su totalidad las diputaciones, que debían quedar constituidas de nueva planta a finales de abril con los diputados recién elegidos.

\footnotetext{
${ }^{3}$ Secretaría General de la Diputación Provincial. Libro de Actas, sesión del 22.05.1944, folio 171v. Con anterioridad, la Comisión Gestora, el 1 de noviembre de 1942, le había elegido, cuando era alcalde de Villamuriel de Campos, procurador en Cortes en representación de los municipios de la provincia vallisoletana. Las primeras Cortes, según convocatoria que recibe de su presidente Esteban Bilbao, quedaron constituidas el 16 de marzo del año siguiente. Represa será reelegido procurador en Cortes en las sesiones celebradas el 7 de abril de 1946 y el 24 de abril de 1949, respectivamente.

417 de julio de 1945, BOE, 18 de julio, pp. 360-384.

5 Art. 229. Cesan igualmente cuando pierden la condición de alcaldes y concejales o de representantes por los que fueron elegidos.

${ }^{6}$ El cargo de diputado provincial como el de regidor era obligatorio y gratuito, contribuyendo a una posible menor dedicación de los elegidos y al mismo tiempo al fortalecimiento de la figura del presidente. C. Molinero, P. Ysas en Borja De RiQuer (dir.): Historia de la Diputación de Barcelona, III, Barcelona, 1988, p. 43.
} 
Resulta superfluo reiterar que esta norma legal vigente durante el franquismo marca el ritmo autoritario y centralista en las instituciones. Y, como una consecuencia ineludible, barre cualquier contenido político identificando la tarea de la Diputación con la de un organismo gestor de los servicios que le eran encomendados y, al mismo tiempo, inspeccionados y controlados desde el Gobierno 7 . Asimismo, importa recordar el modo de seleccionar los diputados a través de la representación municipal y corporativa. En el primer caso, la institución provincial dispone de un diputado por cada partido judicial elegido de forma indirecta por los compromisarios que designen sus ayuntamientos entre sus alcaldes y concejales. Cualquier cese en estos cargos provocará el abandono del puesto de diputado, manteniéndose vacante el cargo hasta la renovación trienal siguiente.

A este bloque de diputados se añadía otro corporativo, en número menor de la mitad del sector anterior, como representantes de las corporaciones y entidades radicadas en la provincia ${ }^{8}$. Todas ellas tenían el derecho de proponer candidatos en número triple al de vacantes. En concret, la Universidad recibió cada tres años el oficio por el que el gobernador civil (ver el modelo remitido el 7 de marzo de $1955^{9}$ ) comunica que, por figurar en el registro de corporaciones, debe designar los compromisario y candidatos más aptos para el desempeño del cargo de diputado provincial. Cierto que las propuestas universitarias parecen solventarse como asuntos de trámite, según indica la repetición de candidatos, que en algún año son las mismas personas antes propuestas para concurrir a las elecciones municipales. Desde luego con escaso éxito, salvo en los comicios del año 1949 cuando fue elegido Emiliano Berzosa, profesor en la facultad de Medicina.

\footnotetext{
7 GonzÁlez Casanova resaltó el carácter bifronte de la Diputación en los años de la Restauración asumiendo el gobernador la vertiente política, mientras que la corporación provincial asumía la administrativa. El Decreto de 10 de octubre de 1958 amplía las funciones, fundamentalmente en directrices operativas, del gobernador civil sobre la diputación provincial. Todavía en 1974 el vicepresidente del Gobierno GARCíA HERNÁNDEZ veía a las diputaciones como «cenicientas» que debían salir de esta situación. Libertad (L) 27.02.74, $3^{\mathrm{a}}$. Art. Diputaciones firmado por GAYTÁN.

${ }^{8}$ El modelo repetido cada tres años puede ser el remitido por el gobernador RuIZ OCAÑA a la Universidad el 12.03.1958. Archivo de la Universidad de Valladolid (AUVA) leg. 1554. La primera vez consta en el libro de actas de la junta de gobierno del 13 de marzo de 1949: «se leyeron por el secretario las comunicaciones relativas a la inclusión de la Universidad en la relación de entidades culturales con derecho a tomar parte en las elecciones antes citadas y a las personas elegidas para el cargo de diputado provincial. Efectuada la elección resultó elegido compromisario por unanimidad el ilustrísimo señor don Ricardo Royo-Villanova, decano de la facultad de Medicina. Previa deliberación se acordó proponer al excelentísimo señor gobernador civil candidatos de esta Universidad a los señores Ricardo Royo Villanova, Emiliano Berzosa, Saturnino Rivera, Juan del Rosal y Ricardo GRANADOS».
}

9 AUVA leg. 1559. 


\section{COMPROMISARIOS Y CANDIDATOS A DIPUTADOS PROVINCIALES POR LA UNIVERSIDAD DE VALLADOLID}

\begin{tabular}{|l|l|l|l|}
\hline Fuente & Fecha & Compromisario & Candidato \\
\hline AUVA lib.3045, fol. 54 & 13.03 .1949 & R. Royo-Villanova & $\begin{array}{l}\text { Ricardo Royo-Villanova, Emiliano Berzosa, Saturnino } \\
\text { Rivera, Juan del Rosal, Ricardo Granados }\end{array}$ \\
\hline AUVA lib. 3045, fol.121 & 16.03 .1952 & Juan del Rosal & Cayetano Mergelina, Angel Allúe \\
\hline AUVA lib. 3045, fol.138v & 13.03 .1955 & Salvador Senent & Angel Huarte \\
\hline AUVA lib. 3045, fol.158v & 23.03 .1958 & Alejandro Herrero & Angel Huarte, Antonio Martín Descalzo \\
\hline AUVA lib. 3045, fol. 188 & 19.03 .1961 & Filemón Arribas & Salvador Senent, Antonio P. Casas, Angel Allúe \\
\hline AUVA lib. 1340, fol. 31 & 22.03 .1964 & Antonio Pérez Casas & Salvador Senent, Ángel Allúe \\
\hline AUVA lib. 1340, fol. 86v & 19.03 .1967 & Perfecto Ga Jalón & Pedro Alvarez Quiñones, Ernesto Sánchez Villares \\
\hline ADP I-4629 & 25.03 .1976 & & Ramón Velasco Alonso \\
\hline
\end{tabular}

Antes de seguir adelante, es ocioso advertir la discrecionalidad ejercida por el gobernador, con potestad para reducir las propuestas que recibe, y plasma a la hora de elevar a definitiva la lista de candidatos remitida a la junta electoral del censo, que Carme Molinero califica de «colocados por el gobernador» ${ }^{10}$. Este uso y abuso desvela el control del gobernador y jefe provincial del Movimiento ${ }^{11}$, conforme advertimos cuando analizamos los comicios municipales. Asimismo, según recordatorio que reciben los gobernadores civiles, incluso en fecha tan tardía como eran las vísperas de las votaciones para diputados provinciales de marzo de 1974: «(no podrán ser propuestos candidatos por entidades y organismos sindicales) quienes no hayan hecho constar expresamente, y por medio de escrito, que reunirán a la propuesta, su adhesión a los Principios del Movimiento y demás Leyes Fundamentales del Reino» ${ }^{12}$. Todo ello, sin desdeñar otras competencias igualmente importantes como era ser presidente nato de la Diputación ${ }^{13}$, que, entre otras muchas veces, en el año 1967 recuerda sin necesidad de hacerlo en ocasión solemne el gobernador José Pérez Bustamante ${ }^{14}$, junto con la capacidad de nombrar y remover alcaldes, en poblaciones inferiores a diez mil habitantes, cuyo alcance era evidente en los meses previos a los comicios provinciales. Además en el partido judicial

${ }^{10}$ Loc. cit., p. 45.

11 Que el mismo Ministerio de la Gobernación no ocultaba en sus Instrucciones a la hora de convocar las elecciones. AGA, Interior, caja 208. El gobernador dirigía la acción política del Gobierno y coordinaba la actuación de los delegados ministeriales, haciendo aplicar todas las disposiciones gubernativas.

12 Orden de 11 de enero de 1974, BOE, 4 de febrero.

${ }^{13}$ Base 37 de la Ley de Bases. Art. 212. El gobernador es la primera autoridad de la provincia, representante del Gobierno y delegado permanente del Poder central.

14 ADP sesión extra 01.04.1967, fol. 112: PÉREZ BUSTAMANTE se muestra satisfecho por acudir a la constitución (de la nueva Diputación), no sólo porque la Ley establece la Presidencia nata de los Gobernadores, sino porque durante 16 años (en la Diputación Provincial de Santander) estuve sentado en una mesa como ésta, vinculado y encariñado con la labor provincial». 
de las capitales, cuya población superase los cien mil habitantes los compromisarios del ayuntamiento elegirán de entre los concejales un representante por cada 500000 habitantes, o fracción ${ }^{15}$. Una Ley posterior ${ }^{16}$, que modifica la Ley de Bases, entró en vigor desde las elecciones celebradas en 1964 e introdujo representantes de la Organización Sindical previamente votados por los compromisarios sindicales (empresarios y obreros), y cuyos puestos se restarán del sector corporativo que hasta esa fecha cubría cinco puestos en la institución provincial.

No hace falta advertirlo, queda excluida del proceso electoral la provisión del cargo de presidente de la Diputación, cuyo nombramiento pertenece al ministro de la Gobernación, sin establecer la duración en el cargo, y que fue cubierto durante algo más de treinta años por tres presidentes. De todas formas, tanto en la presidencia como en los diputados provinciales, era indispensable la mediación y propuesta previa del gobernador, circunstancia, desde luego, nada novedosa, según certifica para el pasado restauracionista $\mathrm{H}$. Pastrana en su estudio ${ }^{17}$ reservando un epígrafe al gobernador civil "gran elector», y que ahora confirma el uso de las competencias arriba señaladas. Y ejercidas con éxito, según indicamos más adelante y confirman los interesados - por expreso deseo del gobernador civil y jefe provincial del Movimiento, dirá Represa al asumir la presidencia- oportunidad que aprovecha Libertad para confirmar su pedigrí falangista ${ }^{18}$.

\footnotetext{
15 Art. 228.

${ }^{16}$ Ley de 2 de diciembre de 1963 (BOE, 5 de diciembre): Que otorga «la participación en la gestión, defensa y desarrollo de los fines propios de estas corporaciones, que es aspiración reiteradamente expuesta por dicha Organización Sindical». En la convocatoria de elecciones provinciales para la renovación trienal de 1967 (BOPVa n. ${ }^{\circ}$ 50, 01.03.67. Ministerio de la Gobernación, Decreto 301/ 67, art. 5.1) se recuerda la nueva redacción del art. 227 de la Ley de Régimen Local: «Las vacantes correspondientes al grupo de representación corporativa, cuya renovación corresponde en la presente convocatoria, se dividirán en dos mitades, asignándose una de ellas a la representación de las Corporaciones y Entidades económicas, culturales y profesionales, y la otra mitad a la representación de la Organización Sindical».
}

\footnotetext{
${ }^{17}$ La Diputación Provincial de Valladolid, 1875-1930, Valladolid, 1997, 77.

${ }^{18} L$ 09.051944, $6^{\text {a }}$.De su predecesor RoDRíGUEZ FERNÁNDEZ-VILA indica que desde la constitución de las JONS fue entusiasta partidario de ellas, colaborando continuamente con aportaciones al sostenimiento de Libertad. Iniciado el Movimiento Nacional se afilió a Falange. En 1937 fue nombrado jefe de la CNS y en 1939 presidente de la Diputación Provincial. En 1943 era secretario local de la Falange vallisoletana, cargo que simultaneó con el de presidente de la Diputación Provincial. L. 17.05.1944, $1^{\text {a }}$ : Entre las notas biográficas de Juan Represa, el diario jonsista destaca haber nacido en Valladolid hace 34 años, pertenecer a la Vieja Guardia de Falange Española y, por su actuación como voluntario en las centurias Girón y Primera Bandera de Castilla, tiene concedidas dos cruces militares colectivas. Durante los años 1938-1939 fue delegado del SNT en Lérida. Estudió Ciencias Químicas en la Universidad de Valladolid y, al cesar en el cargo de Lérida, fue nombrado alcalde de Villamuriel de CerRato. Procurador en Cortes y secretario provincial del Movimiento.
} 
En cualquier caso, esta institución provincial, resultó menos visualizada para el vecindario capitalino. Sin duda, porque éste apenas estaba involucrado en el proceso electoral. Por eso mismo, el interés de la población vallisoletana quedó desvanecido respecto del que mostró con las elecciones municipales, incluso cuando en éstas únicamente participaban los cabezas de familia para elegir sus representantes por ese tercio. Quizá también contribuyera a este distanciamiento, junto con el escaso/nulo rango político de los diputados, la proximidad de los ediles de la capital, cuya población también percibía de cerca otras instituciones superiores establecidas en ella desde mucho tiempo atrás: Universidad, Capitanía General, Audiencia, Arzobispado... Sin embargo, deberá excluirse de esta valoración, que puede presumirse secundaria, la relevancia del presidente de la corporación provincial sobre todo cuando, en diversas ocasiones, suplía en las ausencias e interinidades al gobernador civil.

\section{UN PROCESO REGLAMENTADO AL DETALLE}

Que se cumple escrupulosamente en todas las elecciones. Una vez promulgada la convocatoria, queda abierto el plazo para inscribirse en el registro especial del Gobierno Civil reservado a las corporaciones y asociaciones culturales, económicas y profesionales. Las juntas directivas deberán elegir en la misma sesión a sus compromisarios y candidatos. Estos últimos sólo adquieren dicho rango después que el gobernador ratifica la propuesta, que, al fin y al cabo, es la que cuenta. Porque en el sector municipal, salvo renuncia expresa de los interesados, todos los alcaldes y concejales son candidatos. Sin embargo, cada ayuntamiento del partido judicial respectivo debe elegir su compromisario en sesión plenaria consistorial reunida al efecto. En el caso del partido judicial de la ciudad, corresponde al ayuntamiento capitalino elegir mediante votación secreta nueve compromisarios. Esta circunstancia señala el peso del consistorio de la capital sobre los demás municipios de la circunscripción, en cada uno de los comicios convocados para elegir al diputado municipal del partido judicial. Además, por rebasar el censo municipal los cien mil habitantes, la ciudad dispone de otros tres compromisarios cuya misión era votar al diputado representante del propio ayuntamiento. Las actas municipales certifican minuciosamente el protocolo seguido en las sesiones de cada consistorio. Primero, debía leerse el decreto con las normas pertinentes y, acto seguido, los capitulares depositan sus votos en la urna por este orden: concejales, tenientes de alcalde y alcalde, según certifica el secretario general del Ayuntamiento indicando el número de votos obtenidos por cada uno de ellos. 
Concluida la sesión electiva de compromisarios, al domingo siguiente concurren todos ellos al palacio provincial para intervenir en la sesión extraordinaria de la junta electoral del censo, siendo su primera medida designar escrutadores. Tarea resuelta fácilmente al recaer tal designación en los compromisarios votantes de mayor y menor de edad. Bastará una semana, al domingo siguiente, para que los diputados electos tomen posesión y desde entonces pueda ejercer sus funciones la nueva corporación provincial.

\section{LAS PRIMERAS ELECCIONES PROVINCIALES DE LA DEMOCRACIA ORGÁNICA (1949)}

Según dijimos, desde el final de la Guerra Civil y hasta esta convocatoria electoral, es decir, durante los diez años precedentes, quedaron establecidas en la Diputación dos Comisiones Gestoras integradas por su presidente y un corto equipo de gestores ( $\mathrm{cinco} / \mathrm{seis}^{19}$ ) en las corporaciones instauradas en 1939 y 1943, respectivamente. En la última, siete meses después de posesionarse la nueva gestora, se efectuará el relevo en la presidencia debido a ser nombrado su titular gobernador civil y jefe provincial del Movimiento de Zamora. A partir del año 1949 la institución dispondrá de dieciséis diputados: once representantes municipales y cinco corporativos.

Aunque el Decreto que convoca las elecciones provinciales propicia la renovación total, tres de los últimos gestores (Berzosa, Gómez Ayllón y Santiago Juárez) permanecerán en sus puestos anteriores, si bien ahora lo hagan con el refrendo obtenido en las elecciones corporativas. En consecuencia, acceden por primera vez los diputados elegidos entre los alcaldes y concejales de los municipios, mientras que los representantes corporativos sólo fueron renovados parcialmente.

La primera convocatoria electoral cumplió con rigor los plazos y normas legales reguladores del proceso; todo lo dispuesto por el Decreto del Ministerio de la Gobernación del 4 de febrero de $1949^{20}$. Como paso previo, todos los ayuntamientos de la provincia cumplieron la obligación de elegir su compromisario en la sesión extraordinaria del pleno munici$\mathrm{pal}^{21}$. Idéntica operación surtió efecto en las juntas directivas de las cor-

\footnotetext{
19 BOPVa 11.07.1944 amplía con uno más el número de gestores.

20 BOE 18 de febrero y BOPVa 21 de febrero.

21 Al ayuntamiento de Valladolid le correspondía elegir 9 compromisarios cada vez que debía renovarse el representante de su partido judicial. En esta primera ocasión, después de escrutarse las pape-
} 
poraciones y entidades oficialmente reconocidas. Todo, en la misma fecha: el 13 de marzo. Al domingo siguiente, los compromisarios ${ }^{22}$ provistos de sus credenciales acudieron al palacio provincial para elegir diputados entre los miembros de las corporaciones municipales de cada partido judicial y también entre los quince candidatos seleccionados por el gobernador civil de la lista que presentaron las treinta y cinco corporaciones provinciales. La votación comienza, y así se mantiene en el futuro, depositando su papeleta los compromisarios, partido por partido comenzando por el de Medina del Campo. El número de pueblos hace que varíe el censo de compromisarios y de sufragios depositados en la urna o su reparto en cada circunscripción. También difiere el resultado del escrutinio de las corporaciones y entidades, debido a tener los electores que pronunciarse sobre los cinco puestos correspondiente a este bloque. La primera de esta sesiones extraordinarias, que tuvo lugar en la sede de la Diputación, comenzó designando dos escrutadores, tarea que asumen los compromisarios de mayor y menor edad: Julián Serrano, del ayuntamiento de Padilla de Duero (79 años) y Jaime Cano Valentín (25 años) que lo era como representante del SEU.

\subsubsection{3}

\begin{tabular}{|l|c|c|c|}
\hline Nombre y apellidos & $\begin{array}{c}\text { Partidos judiciales } \\
\text { /entidades }\end{array}$ & Cargos & Observaciones \\
\hline Juan Represa León & & & Presidente \\
\hline Aurelio Rojo Nomdedeu & Medina del Campo & Alcalde de Medina del Campo & Agricultor \\
\hline José Amigo Torres & Medina de Rioseco & Alcalde de Medina de Rioseco & Almacenista \\
\hline Florentín Moretón Carbajosa & Mota del Marqués & Concejal de Tiedra & \\
\hline Donato Vadillo Buitrón & Nava del Rey & Alcalde de Alaejos & \\
\hline Manuel Martín Sanmartín & Olmedo & Alcalde de Olmedo & \\
\hline Mariano Calderón Arranz & Peñafiel & Alcalde de Peñafiel & \\
\hline Mariano de Paz Álvarez & Tordesillas & Alcalde de Tordesillas & \\
\hline Teodoro Martín Martín & Valoria la Buena & Alcalde Canillas de Esgueva & \\
\hline Telesforo Gordaliza Martín & Villalón & Concejal de Villalón & \\
\hline Manuel Martín Olmedo & Valladolid (p. judicial) & Alcalde de Tudela de Duero & \\
\hline Marcelino Caballero Peña & Valladolid (ayunt ${ }^{\circ}$ ) & Concejal Ayto de Valladolid & Inspector Enseñanza \\
\hline Antolín Santiago Juárez & Entidades & & Abogado \\
\hline Benito Sanz de la Rica & Entidades & & Abogado sec. OS \\
\hline Emiliano Berzosa Recio & Entidades & Universidad & Médico \\
\hline Víctor Gómez Ayllón & Entidades & & Periodista \\
\hline Filemón Arribas Arranz & Entidades & & Catedrático Univers. \\
\hline
\end{tabular}

letas, los 175 votos quedaron repartido de esta suerte y proclamados compromisarios los nueve primeros más votados: Carlos Álvarez Pérez (18 votos), Isaac Rivera (18), Cándido Valdés (18), Pedro de la Fuente (18), José María Salcedo (18), Gratiniano Nieto (17), José Luis GutiérRez (13), Félix Igea (11), José Luis Martín Abril (11). Marcelino CABAllero (8), Anselmo de la IgLeSia (7), Télino García (7), Santiago López (5), Ricardo Sáinz (2), Julián Martínez (1), Luciano Moncada (1), Ramón Pradera (1). AMV 262, sesión extra 13.03.1949, fol. 151v.

22 ADP caja 564, expediente 5724. Según el acta electoral no comparecieron los compromisarios de los ayuntamientos de Barruelo, Peñaflor de Hornija, del partido de Mota del Marqués, y Trigueros del Valle, del partido de Valoria la Buena.

23 Según la fecha de constitución de la Corporación provincial. 
A simple vista, los resultados alumbran ciertas peculiaridades. De los once diputados elegidos por partidos judiciales (uno correspondía directamente al ayuntamiento de la capital, cuya población superaba los cien mil habitantes $)^{24}$, el reparto de votos fue desigual. Mientras que en cinco partidos los diputados vencieron por unanimidad (Medina del Campo, Medina de Rioseco, Peñafiel, Tordesillas, Valladolid), en dos fue preciso recurrir a la edad de los candidatos debido al empate en votos ${ }^{25}$. En otras tres circunscripciones el voto fue mayoritario y suficiente para proclamar los vencedores, siendo postergados los otros candidatos (Nava del Rey, Villalón y Valoria). Entre 32 y 18 votos recibieron los cinco candidatos ${ }^{26}$ que concurrían a estos comicios en nombre de corporaciones y entidades. Por debajo de esta última cifra obtuvieron sufragios: Mariano Llanos Partearroyo (11), Ricardo Royo Villanova (3), Antonio Allúe Morer (3), Jaime Cano Valentín (1) y Aurelio Cidad de la Llave ( un voto).

Ciertamente, los resultados permiten hablar de una cierta confrontación entre los candidatos que aspiran acceder a la corporación provincial. Sin exagerar, pues en este pugilato únicamente intervienen los compromisarios, y desde luego cabe presumir la existencia previa de pactos entre ellos (notorios cuando se produce unanimidad) y muy evidente en la atribución de los nueve votos del ayuntamiento de Valladolid cedidos durante este periodo siempre a favor de los ayuntamientos de Renedo de Esgueva y Tudela de Duero, cuyos alcaldes fueron elegidos diputados por el partido judicial de la capital. Entre otras razones, porque el consistorio vallisoletano tenía asegurada la reserva de plaza para su representante en todas las elecciones.

Aun así, según manifiestan los informes de quienes vigilan la situación -icosa esperada!- no hubo sustos. Buena prueba de ello era este «reparto político» que identifica a los nuevos diputados con su anterior pertenencia o militancia: Falange (6), Agrarios (3), CEDA (1), Unión Patriótica (2), Ninguna (4). Distribuidos profesionalmente de esta suerte: abogados (5), labradores (5), comerciantes (1), industriales (2), profesiones liberales $(4$, médicos $(2)$.

\footnotetext{
${ }^{24}$ La Ley Provincial de 1882 otorgaba la representación provincial a 24 diputados así repartidos: Valladolid-Plaza (4), Valladolid-Audiencia (4), Nava del Rey-Tordesillas (4), Peñafiel-Valoria (4), Rioseco-Villalón (4), Medina del Campo-Olmedo (4).

${ }^{25}$ Florentín MoRetón por el partido de Mota del Marqués recibió once votos, los mismos que Vicente RodRíGueZ GonZÁLEZ, siendo proclamado aquél por su mayor edad. El mismo número de votos (16) recibieron por el distrito de Olmedo MANUEl MARTín y Francisco SAN MARTín, resuelto a favor del primero en razón de su edad.

${ }^{26}$ Antolín de Santiago (32), Benito Sanz de la Rica (30), Emiliano Berzosa (29), Víctor Gómez (27), Filemón ARribas (18). Libertad (L) 22.03.49, $1^{\text {a }}$.
} 


\section{COMIENZA LA NUEVA CORPORACIÓN PROVINCIAL}

Aparte de otros aspectos, el interés de estas primeras elecciones estriba en que marcan el itinerario y el protocolo de todas las demás. Por ello, aunque ahora nos detengamos en ciertos detalles, no habrá necesidad de reiterarlos en las sucesivas. En todas las convocatorias para constituir la nueva corporación provincial, que presiden mancomunadamente el gobernador civil y el presidente de la Diputación, el punto de partida será la lectura por el secretario general del documento acreditativo de la jornada electoral que expide la junta provincial del censo electoral, con el escrutinio final sancionando la relación de diputados electos ${ }^{27}$. Esta sesión presenta dos momentos. El primero, con asistencia de quienes terminan su mandato, aprueba el acta pendiente y sirve para despedir y agradecer la tarea desarrollada por los diputados cesantes. Tras ello, se reanuda la sesión contando con la presencia de los diputados electos que antes de posesionarse del cargo prestan el juramento, en estos términos: «Juro defender los intereses morales y materiales de la provincia dentro del mejor servicio a España y lealtad al Jefe del Estado». Esta fórmula inicial incorporará otros añadidos en los años sucesivos ${ }^{28}$. Acto seguido, el presidente hace uso de las facultades que le confiere el artículo 224 del Reglamento y designa al vicepresidente para que le sustituya en caso de enfermedad o ausencia. Asimismo, nombra a los diputados-vocales en las comisiones obligatorias de la corporación, cuya presidencia ostentará el titular de la institución: Beneficencia y Obras Sociales, Sanidad, Urbanismo y Vivienda, Agricultura, Ganadería y Repoblación Forestal, Educación, Deportes y Turismo, Obras Públicas y Paro Obrero, Hacienda y Economía.

Un acto de esta trascendencia deja huella en los discursos que pronuncian las autoridades asistentes y quien lo hace en nombre de los diputados recién incorporados. Tanto en esta fecha como cada tres años, cuando se renueva el plantel de diputados, perviven las invocaciones falangistas que

\footnotetext{
${ }^{27}$ Las actas de la sesión electoral se conservan en el Archivo de la Diputación y sólo están recogidas parcialmente en los Libros de sesiones de la Diputación Provincial acerca de los candidatos elegidos por partidos judiciales, corporaciones y entidades provinciales.

${ }^{28}$ En 1958, ADP Acta de la sesión extraordinaria del 1 de abril fol. 2v, reza así: «Juro servir fielmente a España, guardar lealtad al Jefe del Estado, obedecer las Leyes, defender y fomentar los intereses de la Provincia y ajustar mi conducta a la dignidad del cargo». Que en 1961 es más explícita: «Juro lealtad y acatamiento a los Principios fundamentales del Movimiento Nacional y demás Leyes Fundamentales del reino, servir fielmente a España, guardar lealtad al Jefe del Estado, obedecer y hacer que cumplan las leyes, defender y fomentar los intereses de la Provincia, mantener sus competencias y ajustar mi conducta a la dignidad del cargo». ADP Acta de la sesión de 1 de abril de 1964, fol. 21v.
} 
sólo desaparecen en la fase postrera y en concreto desde que asume la presidencia José Luis Mosquera. Hasta entonces, sus predecesores tendrán especial esmero en utilizar el léxico del régimen y de modo singular la apelación falangista cuando se dirigen a los recién llegados empleando la expresión camaradas diputados, luego sustituida por la más cercana de amigos. Al igual que en otras instituciones, también ahora persiste la memoria del Valladolid en los primeros días de la Guerra Civil, pues, dirá el gobernador Alonso Villalobos: «Un nuevo paso en la doctrina falangista se da en estos momentos en todos los organismos provinciales de España (debiéndose recordar a Valladolid) por su actuación decisiva en los momentos difíciles de España, ya que fue la ciudad del Alzamiento». Una remembranza a la que se añade, en la renovación de 1955, como norma de conducta la propia del jonsismo vallisoletano (invocada por la Gestora en $1944^{29}$ ), que actualiza el presidente Berzosa: «Camaradas diputados: La provincia de Valladolid nos mira y nos mira también personalmente el Caudillo de Castila, y aquellos camisas azules valisoletanos que en aquel glorioso 18 de Julio salieron de sus hogares cantando himnos de ilusiones y de gloria para no regresar jamás, dando por Dios y por la Patria lo más que puede darse en la vida, que es la vida misma, en sus mejores años». Siempre concluidos con los gritos rituales de Viva Franco, Arriba Espa$\tilde{n} a^{30} \mathrm{y}$, en su caso, con el canto del Cara al Sol${ }^{31}$.

Como colofón de esta asamblea provincial los diputados debieron elegir al procurador en Cortes representante de la corporación provincial. De acuerdo con la Ley de la Jefatura del Estado de 9 de marzo de 1946, además de los representantes de los municipios de cada provincia ${ }^{32}$, correspondía elegir entre sus miembros un representante de cada Diputación. En este solemne acto se cumplió la elección del representante para la legislatura 1949-1952, que en esta fecha y en lo sucesivo invariablemente recaerá en su presidente. Ya es notorio que en este primer momento tres dipu-

\footnotetext{
29 Lo hace Víctor GómEz AYLlón, como presidente interino, en la ceremonia de posesión del presidente Juan Represa: «Camarada Represa, ve en nosotros, te lo prometemos, no esperanza, sino firme seguridad de unidad, colaboración, lealtad y perseverancia en el trabajo (...). A falta de valía y capacidad, la condición, fervor y voluntad y disciplina falangistas -calidad de la que nos ufanamos con sencilla y soberbia humildad- serán con la ayuda de Dios las palancas que nos moverán y el yugo con que caminaremos en la dura misión de responsabilidad que se nos ha encomendado por la Falange para servir a Valladolid y a España». ADP, Actas 02.04.1944, fol. 171v.

30 ADP, Libro de actas, sesión 02.04. 1955, fol. 4v.

31 Sesión del 17.02.1955, fol. 182: toma de posesión del presidente BERZOSA.

32 Para representar a los municipios de la provincia seguía vigente el «consejo» de la Secretaría General del Movimiento de promover la candidatura única en la persona «fuertemente unida al Movimiento, al que en lo sucesivo pueda a informar y asesorar sobre el estado de la corporación local de su provincia». AGA SGM DNP. Circular 53, caja 319.
} 
tados postulen la aclamación ${ }^{33}$, que aunque agradece no acepta el presidente Represa, pues «debe procederse a la elección, dado que la unanimidad ha de quebrarse al dar él su voto al diputado de mayor edad». Y así fue. El presidente Juan Represa obtuvo 16 votos y uno el diputado Manuel Martín Sanmartín. En las elecciones sucesivas, el presidente tendrá el respaldo unánime de los compañeros de corporación convocados para la nueva legislatura cada tres años días después de tomar posesión los nuevos diputados y renovarse la Diputación.

\section{LA PRIMERA RENOVACIÓN TRIENAL DE LA DIPUTACIÓN}

\section{RENOVACIÓN TRIENAL DE DIPUTADOS PROVINCIALES}

\begin{tabular}{|l|c|c|c|c|c|c|c|c|c|}
\hline $\begin{array}{l}\text { Representantes Municipales } \\
\text { Partidos judiciales }\end{array}$ & 1949 & 195234 & 1955 & 1958 & 1961 & 1964 & 1967 & 1971 & 1974 \\
\hline Medina del Campo & $\mathrm{X}$ & & $\mathrm{X}$ & $\mathrm{X}$ & $\mathrm{X}$ & $\mathrm{X}$ & $\mathrm{X}$ & & $\mathrm{X}$ \\
\hline Medina de Ríoseco & $\mathrm{X}$ & & $\mathrm{X}$ & & $\mathrm{X}$ & & $\mathrm{X}$ & $\mathrm{X}$ & $\mathrm{X}$ \\
\hline Mota del Marqués & $\mathrm{X}$ & & $\mathrm{X}$ & $\mathrm{X}$ & $\mathrm{X}$ & & $\mathrm{X}$ & & $\mathrm{X}$ \\
\hline Nava del Rey & $\mathrm{X}$ & & $\mathrm{X}$ & $\mathrm{X}$ & $\mathrm{X}$ & & $\mathrm{X}$ & $\mathrm{X}$ & $\mathrm{X}$ \\
\hline Olmedo & $\mathrm{X}$ & $\mathrm{X}$ & & $\mathrm{X}$ & & $\mathrm{X}$ & & $\mathrm{X}$ & \\
\hline Peñafiel & $\mathrm{X}$ & $\mathrm{X}$ & & $\mathrm{X}$ & & $\mathrm{X}$ & $\mathrm{X}$ & $\mathrm{X}$ & $\mathrm{X}$ \\
\hline Tordesillas & $\mathrm{X}$ & $\mathrm{X}$ & & $\mathrm{X}$ & & $\mathrm{X}$ & & $\mathrm{X}$ & \\
\hline Valoria la Buena & $\mathrm{X}$ & & $\mathrm{X}$ & & $\mathrm{X}$ & & $\mathrm{X}$ & & $\mathrm{X}$ \\
\hline Villalón de Campos & $\mathrm{X}$ & & $\mathrm{X}$ & & $\mathrm{X}$ & & & $\mathrm{X}$ & $\mathrm{X}$ \\
\hline Valladolid (pdo judic) & $\mathrm{X}$ & $\mathrm{X}$ & & $\mathrm{X}$ & & $\mathrm{X}$ & & $\mathrm{X}$ & \\
\hline Valladolid (ayuntamto) & $\mathrm{X}$ & $\mathrm{X}$ & & $\mathrm{X}$ & & $\mathrm{X}$ & & & $\mathrm{X}$ \\
\hline $\begin{array}{l}\text { Corporaciones y entidades } \\
\text { económicas, culturls, profesnls }\end{array}$ & & & & & & & & & \\
\hline & $\mathrm{X}$ & $\mathrm{X}$ & & $\mathrm{X}$ & & $\mathrm{X}$ & & $\mathrm{X}$ & $\mathrm{X}$ \\
\hline & $\mathrm{X}$ & $\mathrm{X}$ & & $\mathrm{X}$ & & $\mathrm{X}$ & & $\mathrm{X}$ & $\mathrm{X}$ \\
\hline & $\mathrm{X}$ & & $\mathrm{X}$ & & $\mathrm{X}$ & & $\mathrm{X}$ & $\mathrm{X}$ & \\
\hline & $\mathrm{X}$ & & $\mathrm{X}$ & & $\mathrm{X}$ & & $\mathrm{X}$ & & \\
\hline & & & $\mathrm{X}$ & & $\mathrm{X}$ & & $\mathrm{X}$ & & \\
\hline Organización Sindical & & & & & & & $\mathrm{X}$ \\
\hline & & & & & $\mathrm{X}$ & $\mathrm{X}$ \\
\hline
\end{tabular}

33 La propuesta parte del diputado Santiago JuÁREZ, que hacen suya los diputados RoJo y GómEZ Ayllón, y así expresan: «Está en el ánimo de todos los señores diputados que el nombramiento recaiga sobre el señor presidente Represa ya que le ha desempeñado con la máxima competencia por el conocimiento de los problemas y necesidades de la Provincia, estima no es necesario proceder a la elección debiendo hacerse por aclamación». ADP, Actas 02.04.1949, fol. 4v.

34 En esta primera renovación parcial se apela a los diputados de mayor y menor edad así como a las vacantes producidas desde el establecimiento de la anterior corporación. 
Transcurrido el primer trienio, correspondía renovar la mitad de los elegidos en todas las instituciones de la administración local (ayuntamientos, diputaciones, cabildos insulares). Según establecía la norma, esta primera vez, sin haberse cumplido el sexenio para el que fueron elegidos, cesaron los diputados de mayor y menor edad de cada grupo debiendo proveerse sus vacantes en los comicios de 1952. Fue en la sesión extraordinaria del día 12 de marzo cuando los diputados conocieron la comunicación del gobernador civil indicando a quienes correspondía cesar. Los diputados por los partidos judiciales: Manuel Martín San Martín, por el de Olmedo, nacido el 30 de septiembre de 1888; Mariano de Paz Álvarez, por el de Tordesillas, nacido el 24 de enero de 1897; Manuel Martín Olmedo, por el de Valladolid, nacido el 21 de enero de 1921. Por entidades: Filemón Arribas Arranz, nacido el 22 de noviembre de 1903, Antolín de Santiago Juárez, nacido el 2 de octubre de 1918. También debían cubrirse las vacantes producidas durante el trienio: Mariano Calderón Arranz, diputado del partido de Peñafiel, por haber cesado de alcalde, y Mariano Caballero Peña, diputado representante del ayuntamiento de Valladolid, por concluir su mandato como concejal. Bien es cierto que apenas se notó la renovación del anterior equipo provincial, pues de los siete cesantes, cuatro fueron reelegidos aunque dos cambiaron el origen de su representación.

Según el escrutinio celebrado el 23 de marzo les sustituyeron, al celebrarse la sesión constitutiva el 2 de abril, los nuevos diputados ${ }^{35}$ :

En la ceremonia inaugural del nuevo equipo de diputados (sesión 02.04.52), Filemón Arribas, en nombre de los salientes, pronuncia las protocolarias palabras de despedida, a las que responde el presidente.

\footnotetext{
${ }^{35}$ ADP caja 578 exped. 6303. En la Memoria de actividades de las corporaciones Provincial y Municipal del año 1953, el gobernador A. MUÑOZ CALERO repasa ala constitución de la Diputación y sus actividades. Archivo de la Delegación del Gobierno Valladolid (ADGC) DA leg.45. También en DA leg. 181: relación de personas que integran la Diputación el 1 de agosto de 1952 y noticias referentes a los años 1955 y 1959.
} 


\subsubsection{2}

\begin{tabular}{|c|c|c|c|}
\hline Juan Represa León ${ }^{36}$ & & & Presidente \\
\hline Víctor Gómez Ayllón ${ }^{37}$ & Entidades & & Vicepte, periodista \\
\hline Aurelio Rojo Nomdedeu ${ }^{38}$ & Medina del Campo & Alcalde de Medina del Campo & Agricultor \\
\hline José Amigo Torres & Medina de Rioseco & Alcalde de Medina Rioseco & \\
\hline Florentín Moretón Carbajosa $^{39}$ & Mota del Marqués & Alcalde de Tiedra & Almacenista \\
\hline Teodosio Martín Martín & Valoria la Buena & Alcalde de Canillas Esgueva & \\
\hline Donato Vadillo Butrón & Nava del Rey & Alcalde de Alaejos & \\
\hline Emiliano Berzosa Recio ${ }^{40^{*}}$ & Entidades & & Médico \\
\hline Benito Sanz de la Rica & Entidades & & Abogado, sec. OS \\
\hline Filiberto Santiago Santiago & Olmedo & Alcalde de Olmedo & \\
\hline Victoriano Lerma Rodríguez & Peñafiel & Alcalde de Peñafiel & \\
\hline Mariano Paz Álvarez & Tordesillas & Alcalde de Tordesillas & \\
\hline Telesforo Gordaliza Martín & Villalón & Concejal Villalón de Campos & \\
\hline Manuel Martín Olmedo & Valladolid(p. judicial) & Alcalde de Tudela de Duero & \\
\hline Antolín de Santiago Juárez ${ }^{*}$ & Valladolid (ayunt $^{\circ}$ ) & Concejal Ayto de Valladolid & Abogado, del. Cult. P. \\
\hline Marcelino Caballero Peña $^{41}$ & Entidades & & Inspector Enseñanza \\
\hline Ricardo Sáiz Díaz-Lamadrid & Entidades & & Militar \\
\hline
\end{tabular}

Esta vez la elección de procurador en Cortes tiene lugar en la sesión del 20 de abril. En ella no se produce manifestación alguna, siendo llamados los diputados a votar por orden alfabético y elegido el presidente Represa por quince votos; Víctor Gómez Ayllón ${ }^{42}$ recibe un voto. Antes de levantar la sesión, el presidente propone que se envíen telegramas de adhesión y lealtad al Jefe del Estado, ministros de la Gobernación, Secretario general del Movimiento y director general de Administración Local, y así se acuerda.

Transcurridos algo más de dos años desde que inicia su andadura esta nueva corporación, Juan Represa abandona la presidencia. Según se

${ }^{36}$ Sustituye a Eusebio RodRíguez Fz. Vila, nombrado gobernador y jefe provincial de Zamora , siendo propuesto por el gobernador Romojaro presidente sin haber sido gestor de la Diputación. L. 22.05.44. Aceptada la dimisión en la sesión del 2 de agosto de 1954, Víctor GómEZ AYLLÓn ejerce como presidente accidental desde 29.07.54 a 17.02.55.

${ }^{37}$ Nombrado el 24.04.49.

38 Elegido para la legislatura 1952-1955 procurador en Cortes por los municipios de la provincia. Obtuvo 225 votos y dos papeletas en blanco. ADP Sesión 16.04.1952, fol. 202v. Antes de entrar en el orden del día el presidente pide que conste en Acta la felicitación al diputado A. Rojo por haber sido elegido procurador en Cortes por los municipios de la provincia en representación de la misma.

39 Empatado a 11 votos con Vicente RodRíGUEZ GonZÁLEZ, es proclamado por ser de mayor edad.

${ }^{40}$ Perteneció a la gestora nombrada el 16.12.43.

${ }^{41}$ Entre los fidelísimos. Ya participó en la Gestora de 1939, Cf. J.M. PALOMARES, El primer franquismo, 61.

${ }^{42}$ En las elecciones de 1955, será proclamado procurador en Cortes el presidente Berzosa al recibir quince votos y A. REOJO, uno; será reelegido en 1958 y 1961 por quince/dieciséis votos favorables y uno en blanco, respectivamente. Actas de las sesiones del 17 de abril de 1955, 13 de abril de 1958 y 16 de abril de 1961. 
comunica a los diputados ${ }^{43}$ : «ya que se encuentran justificados los motivos de índole particular en que fundamenta (la dimisión del cargo de presidente de la Diputación)» debiéndose hacer cargo de la presidencia el vicepresidente ${ }^{44}$ hasta que sea nombrado el nuevo titular. Desde esa fecha, la interinidad cubierta por Víctor Gómez Ayllón duró algo más de seis meses y medio, cuando el nuevo gobernador Jesús Aramburu promoverá para el cargo a Emiliano Berzosa ${ }^{45}$. Éste era, sin duda, buen conocedor de la institución pues participó en ella desde 1943 y renovado como candidato por la Universidad en las elecciones de 1949, sirviéndola durante casi veinticinco años hasta ser relevado en la presidencia por José Mosquera en enero de 1968. Para recordar que el cargo era ajeno a las urnas y dependiente de la primera autoridad civil, la posesión del nuevo responsable de la corporación, tuvo efecto, en una ceremonia que presidió el gobernador Aramburu, en vísperas de celebrarse las elecciones trienales de diputados en $1955^{46}$.

\section{LAS ELECCIONES DE 1955}

Convocadas por Decreto del Ministerio de la Gobernación el once de febrero, tenían por objeto sustituir a los diputados que cumplían seis años en el cargo ${ }^{47}$, señalando como fecha electoral el domingo 20 de marzo, cuando los votantes tenían el compromiso de elegir nueve diputados $(6$ representantes municipales de los partidos judiciales y 3 por entidades ${ }^{48}$ ).

\footnotetext{
${ }^{43}$ Sesión extraordinaria de 2 de agosto de 1954, fol. 120.

${ }^{44}$ Que en la misma sesión pone de relieve la labor del camarada y amigo Represa en el desempeño del cargo, al tiempo que solicita la colaboración de todos.
}

45 Archivo Municipal de Valladolid (AMV) 241 (permanente) 23.02.55, 114 satisfacción por el nombramiento de Berzosa como presidente de la Diputación. L 17. 02.55, $1^{\circ}$. El periódico destaca entre los datos biográficos del nuevo presidente pertenecer a la promoción de médicos que terminó la carrera en 1931 y ser profesor adjunto de la Facultad de Medicina. Delegado provincial de Sanidad, organizó la Obra Sindical «18 de Julio» y los servicios del Seguro de Enfermedad en la capital y provincia, hasta la fecha de asumir la presidencia de la Diputación. A su incansable labor se debe el establecimiento de la Policlínica «José Antonio Girón» en la ciudad. Para sustituirle en la dirección de la OS «18 de Julio» es nombrado Modesto Sagarra.

${ }^{46}$ Convocatoria extraordinaria para el 17 de febrero de 1955 y orden del día. BOP extraordinario del 16 de febrero de 1955.a.

${ }^{47}$ BOPVa n. $^{\circ} 45,24.03 .1955$.

48 ADP caja 1348, expediente 10671. Resultan elegidos Aurelio RoJo (Medina del Campo) con 21 votos de los 21 compromisarios, Rafael HERRERo (Medina de Rioseco) 21/21, Ricardo IzQUIERDO (Mota) 18/18, Aureliano García (Nava) 9/9, Salustiano García (Valoria) 24/24, Aurelio Pardo (Villalón) 37/37. En el grupo de las 47 entidades que aprueba el gobernador civil sólo acuden cuarenta con sus credenciales y votan, con este reparto de votos: Miguel GARCÍA ABRIL, 35 votos, Anto- 
Permanece por ser reelegido el anterior representante de Medina del Campo, mientras que se renuevan los diputados de los partidos de Medina de Rioseco, Mota del Marqués, Nava del Rey, Valoria la Buena y Villalón de Campos. También el sector de entidades aporta tres nombres nuevos.

\subsubsection{5}

\begin{tabular}{|c|c|c|c|}
\hline Emiliano Berzosa Recio $^{49}$ & & & Presidente \\
\hline Aurelio Rojo Nomdedeu ${ }^{50}$ & Medina del Campo & Alcalde de Medina del Campo & Vicepresidente \\
\hline Victoriano Lerma Rodríguez & Peñafiel & Alcalde de Peñafiel & \\
\hline Mariano de Paz Álvarez ${ }^{51}$ & Tordesillas & Alcalde de Tordesillas & \\
\hline Manuel Martín Olmedo & Valladolid (p. judicial) & Alcalde de Tudela de Duero & \\
\hline Antolín de Santiago Juárez & Valladolid (ayunt ${ }^{\circ}$ ) & Concejal Ayto de Valladolid & \\
\hline Marcelino Caballero Peña ${ }^{52}$ & Entidades & & Inspector Enseñanza \\
\hline Ricardo Sáinz Díaz-Lamadrid & Entidades & & Militar \\
\hline Rafael Herrero Sánchez & Medina de Rioseco & Alcalde de Medina de Rioseco & \\
\hline Ricardo Izquierdo García & Mota del Marqués & Alcalde de Barruelo & \\
\hline Aureliano García Gago & Nava del Rey & Alcalde de Nava del Rey & \\
\hline Salustiano García Gutiérrez & Valoria la Buena & Alcalde de Cabezón Pisuerga & \\
\hline Aurelio Pardo Antón & Villalón & Alcalde de Fontihoyuelo & \\
\hline Filiberto Santiago Santiago & Olmedo & Alcalde de Olmedo & \\
\hline Miguel García Abril González & Entidades & & Industrial \\
\hline Antonio Molleda Garcés & Entidades & & \\
\hline José María Casado Travesí & Entidades & & Corredor comercio \\
\hline
\end{tabular}

La toma de posesión tiene lugar en el palacio provincial el 2 de abril ${ }^{53}$ cumpliéndose el protocolo vigente, es decir: juramento que prestan los diputados, reparto de comisiones y designación de vicepresidente en la persona del diputado-alcalde de Medina del Campo Aurelio Rojo. Todos ellos reciben la bienvenida del presidente Berzosa, quien presenta «a los camaradas diputados una visión del pasado y del campo de acción en que hemos de trabajar».

\section{LA NUEVA DIPUTACIÓN DE 1958}

Hasta ahora resulta ser el cambio trienal más completo. Sólo continúan en el cargo cinco diputados de la corporación anterior (tres repre-

nio Molledo (32), José M. Casado (23), Fortunato Crespo Cedrún (13), Melanio Calvo Criado (4), Eudoxio López Doncel (3), Jesús Molinero Peñafiel (2), Francisco Antón Alonso (1).

49 Toma posesión el 17.02.55. Vide biografía L 17.02.55.

50 Reelegido.

51 Reelegido.

52 Sustituido al cesar de concejal de Valladolid.

53 ADP Acta sesión extraordinaria 02.04.1955 fols.1-5. ADGC DA-181: integrantes de la Diputación Provincial en 1955. L. 03.04.1955. 
sentantes de entidades y dos de municipios) sobre un total de dieciséis diputados. Sin duda, esta oportunidad fue aprovechada para cumplir la Instrucción ${ }^{54}$ de la Superioridad que recomendaba la mayor renovación posible, así como evitar reelecciones, siendo prioritaria la juventud y eficacia de los candidatos. Son elecciones que no deben mezclarse con las de procuradores, según recuerda el gobernador en la Circular que remite a los alcaldes respecto de los compromisarios participantes en renovar los cargos. El Decreto de 21 de febrero fija la convocatoria para el 30 de marzo ${ }^{55}$. Previamente, en la sesión de aquélla fecha, el Acta consigna el cese del concejal del ayuntamiento de la ciudad Antolín de Santiago, que acarrea la pérdida de la condición de diputado y vicepresidente $^{56}$. Le sucederá en este último cargo Rafael Serrano, alcalde de Medina de Rioseco, desde la fecha en que quedó constituida la Diputación el 1 de abril ${ }^{57}$. Una semana antes, el ayuntamiento de Valladolid eligió como de costumbre los nueve y tres compromisarios para votar al diputado del partido judicial y del propio ayuntamiento ${ }^{58}$, respectivamente. Con los resultados electorales del 30 de marzo que certifica la Junta electoral ${ }^{59}$, la Diputación recibe a los diputados electos en acto solemne que preside su titular Emiliano Berzosa, manteniéndose el protocolo habitual así como el reparto de funciones entre los recién incorporados.

\footnotetext{
54 AGA Interior, caja 208.

55 BOPVa n. ${ }^{\circ}$ 51, 03.03.1958.

56 Como resultado de las elecciones municipales celebradas en 1957 cesa junto con los concejales del tercio familiar elegidos en 1951, al constituirse el nuevo ayuntamiento, el día 2 de febrero de 1958.

57 Acta de la sesión del 1 de abril de 1958, fol. $2 \mathrm{v}$.

58 AMV 265, 23.03.58

59 ADGC DA 182: relación de los diputados en 1959 y que prolongan su mandato hasta 1964. Los resultados de la elección de 1958 ( ADP caja 1348, expediente 10672) confirman que en este caso y en la siguiente renovación trienal se atenúan, cuando no desaparecen, las unanimidades en el reparto de votos y aumentan el número de candidatos que son tenidos en cuenta por los compromisarios. En Medina del Campo reciben votos el alcalde de esta villa Juan BAUTista García MeLLADO (12 votos) y Andrés PÉREZ EstÉvEZ, alcalde de Rubí (9 votos). Los compromisarios de Mota del Marqués reparten su voto entre cuatro candidatos, el de Peñafiel entre tres, y la misma proporción acompaña el escrutinio de los partidos de Valoria y Tordesillas.
} 


\subsubsection{8}

\begin{tabular}{|l|l|l|l|}
\hline Emiliano Berzosa Recio & & & Presidente \\
\hline Rafael Herrero Sánchez & Medina de Rioseco & Alcalde de Medina de Rioseco & Vicepresidente \\
\hline Aurelio Pardo Antón & Villalón & Alcalde de Fontihoyuelo & \\
\hline Miguel García Abril González & Entidades & & \\
\hline José M. Casado Travesí & Entidades & & \\
\hline Antonio Molleda Garcés & Entidades & & \\
\hline Juan Bautista García Mellado & Medina del Campo & Alcalde de Medina del Campo & \\
\hline Antonio Pérez Minayo Tabarés & Mota del Marqués & Alcalde de Urueña & Propietario \\
\hline Constancio Muñumer Blanco ${ }^{60}$ & Nava del Rey & Alcalde de Siete Iglesias & Maestro \\
\hline Eusebio Valero Lorenzo & Olmedo & Alcalde de Olmedo & \\
\hline Angel Escribano de la Torre & Peñafiel & Alcalde de Peñafiel & \\
\hline Julián Martínez Ruiz & Valoria la Buena & Alcalde de Villanueva Infantes & \\
\hline Féliz Calvo Casasola & Tordesillas & Alcalde de Villalar Comuneros & \\
\hline José María García Gutiérrez & Valladolid(p. judicial) & Alcalde de Renedo Esgueva & Propietario, Abogado \\
\hline Luis Fernández Fernández-Madrid & Valladolid(ayunt $\left.{ }^{\circ}\right)$ & Concejal Ayto de Valladolid & Funcionario \\
\hline Carlos A. Castro Castro & Entidades & & Catedrático E Normal \\
\hline José (Jesús) Gil Calvo & Entidades & & \\
\end{tabular}

\section{LAS ELECCIONES DE 1961}

En la primavera de 1961 la Diputación cambió la mitad de sus miembros: ocho diputados. Cumplía fielmente la renovación por mitad en cada trienio prevista desde el principio por la Ley. Sólo un diputado (Juan Bautista García Mellado, alcalde de Medina del Campo) fue reelegido. A través de sus compromisarios las entidades sustituyen a sus tres representantes que accedieron al cargo en 1955. Mientras que el sector de los municipios cambió a cinco de los posesionados en 1958. Dos causas justifican este cambio: haber cesado como alcaldes, en cuya virtud accedió al cargo de diputados, o porque fuera elegidos hasta cumplirse el mandato de sus predecesores (tres años) sin obtener el refrendo en esta convocatoria.

Hasta el escrutinio final, se cumplieron los plazos establecidos en el Decreto 244/61 de 16 de febrero: votación de compromisarios (19 de marzo) y de diputados (26 de marzo). Esta vez el ayuntamiento capitalino no eligió compromisarios pues el mandato de sus representantes expiraba tres años después.

En la sesión constitutiva ${ }^{61}$ se recordó al diputado fallecido Ricardo Izquierdo García, representante del partido de Mota en los comicios de 1955. Asimismo, recibe la vicepresidencia José María García Gutiérrez, diputado por el partido de Valladolid.

60 Maestro nacional fallecido el 17.01.67.

61 Acta de la sesión del 1 de abril de 1961, fols. 21-22. 


\subsubsection{1 ${ }^{62}$}

\begin{tabular}{|c|c|c|c|}
\hline Emiliano Berzosa Recio & & & Presidente \\
\hline José María García Gutiérrez ${ }^{63}$ & Valladolid (p.judicial) & Alcalde de Renedo Esgueva & Vicepresidente \\
\hline Eusebio Valero Lorenzo & Olmedo & Alcalde de Olmedo & \\
\hline Ángel Escribano de la Torre & Peñafiel & Alcalde de Peñafiel & \\
\hline Félix Calvo Casasola & Tordesillas & Alcalde de Villalar Comuneros. & Abogado. Profesor \\
\hline Luis Fernández Fz-Madrid & Valladolid (ayunt ${ }^{\circ}$ ) & Concejal Ayto de Valladolid & Funcionario \\
\hline Carlos A. Castro Castro & Entidades & & Catedrático E Normal \\
\hline Jesús Gil Calvo & Entidades & & \\
\hline Juan Bautista García Mellado ${ }^{64}$ & Medina del Campo & Alcalde de Medina del Campo & \\
\hline Félix Rueda Ramos ${ }^{65}$ & Medina de Rioseco & Alcalde de Medina de Rioseco & \\
\hline Miguel Meléndez Rico ${ }^{66}$ & Mota del Marqués & Alcalde de Mota del Marqués & Veterinario \\
\hline Antonio Martín Duque $^{67}$ & Valoria la Buena & Alcalde de Encinas Esgueva & \\
\hline Pedro Abad Martínsantana ${ }^{68}$ & Nava del Rey & Alcalde de Alaejos & \\
\hline Pascual Muñoz Muñoz ${ }^{69}$ & Villalón & Alcalde de Villalón de Campos & \\
\hline Antero Fernández de la $\mathrm{Mela}^{70}$ & Entidades & & \\
\hline Felipe Sánchez Benito & Entidades & & \\
\hline Pedro Sánchez Hernández & Entidades & & Catedrático EU \\
\hline
\end{tabular}

\section{LAS ELECCIONES PROVINCIALES DEL AÑO 1964}

Convocadas ${ }^{71}$ para celebrarse el 26 de marzo, debían cubrir seis plazas de ayuntamientos y dos de entidades, una de ellas por primera vez asignada a la Organización Sindical y votada por los compromisarios sindicales.

El consistorio vallisoletano elige en votación secreta nueve compromisarios $^{72}$, acreditados para participar en la designación del diputado municipal representante del partido judicial: Santiago Montequi (17 votos), López Alonso (16), Finat (15), Zurro (13), Fernández de la Mela (12), Sanjosé (12), Loriente (11), Salinas (11), Ortiz (11). Y los tres concejales: Salinas (11), Tejedor (9), Eduardo La Peña (5) que otorgaron su voto a la concejala María Dolores Pérez Lapeña, como diputada representante del ayuntamiento.

\footnotetext{
62 ADP caja 1348, exped. 10673.

63 Vicepresidente desde el 1 de abril de 1961.

64 Reelegido. En la votación consigue 15 votos por 4 votos César LoRENZO.

65 Consigue 9 votos, por 6 de Ángel GutiéRrez ArgüELlo.

$66 \mathrm{Al}$ obtener 12 votos frente a los 2 de Dionisio BARRIO HigUERA.

67 Obtiene 15 votos, 6 Teodomiro Blanco DíEz y 3 Antonio CEnTEno Herrero.

68 Recibió 4 votos; Julián Hernández SEOAne, 3 y Mariano CAmpos Hernández,1 voto.

69 Recibe 26 votos; Ricardo Ruiz Alonso, 2. Luis BurgueÑo, 2.

70 Fallece el 30 de marzo de 1966.

71 Circular del Gobierno Civil, BOPVa n. ${ }^{\circ}$ 61, 13.03.1964.

72 AMV 267, 22.03.64, fol. 131.
} 
De acuerdo con la convocatoria ${ }^{73}$, la nueva corporación accede oficialmente a sus puestos el 2 de abril, cuando también el diputado Pedro Sánchez recibe del presidente la encomienda de ejercer como vicepresidente de la institución provincial.

\subsubsection{4}

\begin{tabular}{|c|c|c|c|}
\hline Emiliano Berzosa Recio & & & Presidente \\
\hline Pedro Sánchez Hernández & Entidades & Escuela Ingeniería Industrial & Vicepresidente \\
\hline Félix Rueda Ramos ${ }^{74}$ & Medina de Rioseco & Alcalá de Medina de Rioseco & \\
\hline Miguel Meléndez Rico & Mota del Marqués & Alcalde de Mota del Marqués & Veterinario \\
\hline Pedro Abad Martínsantana & Nava del Rey & Alcalde de Alaejos & \\
\hline Antero Fernández de la Mela & Entidades & & \\
\hline Jesús Gil Calvo & Entidades & & \\
\hline José Andrés Coca Ortiz ${ }^{75}$ & Medina del Campo & Alcalde de Medina del Campo & Médico \\
\hline J. Manuel Hurtado Minguela & Olmedo & Alcalde de Llano de Olmedo & Labrador \\
\hline Félix del Campo Esteban & Peñafiel & Alcalde de Corrales de Duero & Farmacéutico \\
\hline Francisco García Alonso & Tordesillas & Alcalde de Bercero & Labrador \\
\hline Antonio Martín Duque & Valoria la Buena & Alcalde de Encinas Esgueva & \\
\hline Pascual Muñiz Muñoz & Villalón & Alcalde de Villalón de Campos & \\
\hline Gerardo Ureta Corcuera & Valladolid(p. judicial) & Alcalde de Renedo Esgueva & Médico \\
\hline $\mathrm{M}^{\mathrm{a}}$ Dolores Pérez Lapeña & Valladolid (ayunt ${ }^{\circ}$ ) & Concejal Ayto de Valladolid & Funcionaria \\
\hline Antonio Ximénez Torres & Entidades & Col. Of. de Médicos & Médico \\
\hline Alfonso Acedo Flórez & Org. Sindical & & Director Agencia viajes \\
\hline
\end{tabular}

\section{LAS ELECCIONES DE 1967}

La prevista convocatoria electoral que promulga el Decreto del Ministerio de la Gobernación 301/67, se difunde a través del diario oficial de la provincia $^{76}$, acompañada de la nueva redacción del artículo 227 de la Ley de Régimen Local, sobre vacantes y entrada en el reparto de la Organización Sindical ${ }^{77}$. Esta vez se incorporan a la corporación provincial seis representantes municipales (cinco nuevos alcaldes y el titular de Villalón, que fue reelegido) y dos representantes en nombre de los sindicatos y entidades ${ }^{78}$.

73 BOPVa 71, 28.03.1964.

74 En la sesión de 28 de febrero de 1966 deja el puesto al haber cesado de alcalde.

75 En la sesión del 27 de febrero de 1967 se lee un comunicado del gobernador civil dando cuenta del cese de José Andrés CocA OrTIZ como alcalde de Medina. Había sido elegido el mismo día que diputado procurador en Cortes por los municipios de la provincia.

76 BOPVa 50, 01.03.1967.

77 Archivo Histórico Provincial de Valladolid (AHPva) AISS 125. Podrán ser elegidos compromisarios todos los afiliados a la OS en las entidades radicadas en la provincia: treinta por cada puesto de representación sindical a cubrir. En el caso de los candidatos a diputados cumplirán estas condiciones: a) ser español mayor de 23 años, b) saber leer y escribir, c) hallarse afiliado en la fecha de publicación del decreto de convocatoria. Para ser proclamado candidato deberá ser: a) propuesto por dos procuradores en Cortes de representación sindical, por acuerdo mayoritario de 25 miembros o un grupo de afiliados a la OS que represente al menos el 20\% del censo; b) desempeñar o haber desempeñado cargo electivo sindical. Ver certificados de la elección 19.01.67, con domicilio, categoría sindical y edades.

78 ADP caja 164, exped. 1441. 
Como sucediera en las elecciones municipales del año anterior, el gobernador civil informa a la instancia superior sobre la filiación política de los candidatos ${ }^{79}$ que obtuvieron sufragios, destacando el número de los propuestos por las corporaciones. En el archivo de la Delegación del Gobierno encontramos una relación detallada de compromisarios por entidades y de sus candidatos, junto con los resultados que, en telegrama oficial urgente fechado el 26 de marzo de 1967, cursa el gobernador al director general de Política Interior:

\begin{tabular}{|c|c|c|c|c|c|}
\hline Vacantes & Partido judicial & Votantes & Candidatos & votos & Filiación política \\
\hline 1 & Medina del Cpo & 19 & Ignacio Sánchez López & 18 & $\mathrm{AF}$ \\
\hline \multirow[t]{2}{*}{1} & Medina Ríoseco & 19 & Andrés Ferreras Pérez & 18 & $\mathrm{AF}$ \\
\hline & & & Darío Martín Martín & 1 & $\mathrm{AF}$ \\
\hline \multirow[t]{2}{*}{1} & $\begin{array}{ll}\text { Mota } & \text { del } \\
\text { Marqués } & \end{array}$ & 22 & Manuel Rico Sevillano & 12 & $\mathrm{AF}$ \\
\hline & & & Daniel Rodríguez Prieto & 10 & $\mathrm{AF}$ \\
\hline 1 & Nava del Rey & 9 & Maximino Pino Alonso & 9 & $\mathrm{AF}$ \\
\hline \multirow[t]{3}{*}{1} & Valoria la Buena & 25 & José González Ruiz & 12 & $\mathrm{AF}$ \\
\hline & & & Heliodoro Rivero Álvarez & 10 & $\mathrm{AF}$ \\
\hline & & & Teodoro Blanco Díez & 2 & $\mathrm{AF}$ \\
\hline 1 & $\begin{array}{l}\text { Villalón de } \\
\text { Camps }\end{array}$ & 36 & Pascual Muñoz Muñoz & 35 & $\mathrm{AF}$ \\
\hline \multirow[t]{11}{*}{2} & Repres. sindical & 56 & Luis Sánchez García & 38 & $\mathrm{AF}$ \\
\hline & & & Godofredo Garabito Gregorio & 24 & $\mathrm{AF}$ \\
\hline & & & Marcial Rodríguez Gutiérrez & 11 & $\mathrm{AF}$ \\
\hline & & & Celiano Vázquez de Prada & 9 & $\mathrm{AF}$ \\
\hline & & & Cándido Vázquez de Prada & 9 & $\mathrm{AF}$ \\
\hline & & & Juan José García García & 6 & $\mathrm{AF}$ \\
\hline & & & Luciano Alonso Muñoz & 3 & $\mathrm{AF}$ \\
\hline & & & Alejandra Bujedo Fernández & 3 & $\mathrm{AF}$ \\
\hline & & & Bonifacio Jiménez Renedo & 3 & $\mathrm{AF}$ \\
\hline & & & Julio Alonso Muñoz & 3 & $\mathrm{AF}$ \\
\hline & & & José Couto Rodríguez & 1 & $\mathrm{AF}$ \\
\hline \multirow[t]{6}{*}{1} & Reprs. entidades & $44^{80}$ & Luis González Echávarri Armendia & 12 & $\mathrm{AF}$ \\
\hline & & & Carlos Campoy García & 11 & $\mathrm{AF}$ \\
\hline & & & José Millaruelo Clemente & 7 & $\mathrm{AF}$ \\
\hline & & & Francisco Lorenzo Belloso & 4 & $\mathrm{AF}$ \\
\hline & & & Ramón Burrieza Pellón & 4 & $\mathrm{AF}$ \\
\hline & & & Isabel Giralda Hidalgo & 1 & $\mathrm{AF}$ \\
\hline
\end{tabular}

79 ADGC SDG 125. Una carpeta con los resultados de las elecciones del tercio de entidades en los 234 pueblos de la provincia aporta con detalle el carácter de la filiación política: afiliación a Falange, adicto al régimen, Vieja Guardia, adicto al movimiento, etc. Según un estadillo de la provincia, fechado el 27.11.1966, de un total de 268 concejales elegidos por el tercio de entidades, se consideran afectos y afiliados 188 , afectos no afiliados 79 y uno independiente.

${ }^{80}$ Aunque eran 49 los compromisarios con derecho a voto. 
A la vista del cuadro precedente, destaca nuevamente la mano del gobernador. En concreto, en el sector de entidades son 78 los candidatos que éstas remiten al Gobierno Civil ${ }^{81}$, reducidas a seis por la primera autoridad provincial: a) Por las entidades económicas: Francisco Lorenzo Belloso (propuesto por la Cámara Oficial Agraria). b) Por las entidades culturales: José Millaruelo Clemente (nominado por la Escuela de Comercio, Caja Rural, Unión de Cooperativas, Cámara Oficial Agraria), Isabel Giralda Hidalgo, por la Asociación de profesores agregados de Instituto. c) Por entidades profesionales: Carlos Campoy García (avalado por el Colegio de Abogados, Asociación de la Prensa y Departamento de Seminarios), Ramón Burrieza Pellón, a propuesta del Colegio de Gestores Administrativos, y Luis González Echávarri, designado por el Colegio de Doctores y Licenciados y por el Círculo «Vázquez Mella».

Un mismo afán selectivo triunfó en el escrutinio de representantes municipales de seis partido judiciales vacantes en dicha convocatoria. Según comunica el gobernador a los alcaldes de todos estos pueblos: «para facilitar a los compromisarios la tarea selectiva y al objeto también de procurar que quien resulte elegido lo sea por un número amplio de votos, evitándose la dispersión de los sufragios, se sugiere a continuación una terna de miembros de las corporaciones locales del partido judicial (camarada....., alcalde de.....), que sin merma de los derechos de cualquier otro, reúnen a juicio de esta Jefatura las condiciones de capacidad e idoneidad requeridas para el ejercicio del cargo de Diputado Provincial ${ }^{82}$. En Hoja aparte constan las ternas aludidas: 1. Partido de Medina del Campo: Giménez Rodríguez, Angel, alcalde de Carpio. Pérez Madrigal, Eduardo, alcalde de Rueda. Sánchez López, Ignacio, alcalde de Medina del Campo. 2. Partido de Medina de Rioseco: Ferreras Pérez, Andrés, alcalde de Medina de Rioseco. Martín Martín, Darío, alcalde de Montealegre. Ruiz Martín, Acisclo, alcalde de Palacios de Campos. 3. Partido de Mota del Marqués: Álvarez Pinilla, Lorenzo, alcalde de Villardefrades. Rico Sevillano, Manuel, alcalde de Casasola de Arión. Rodríguez Prieto, Marcial, alcalde de Tiedra. 4. Partido de Nava del Rey: Nieto Martín, Serafín, alcalde de Torrecilla de la Orden. Pino Alonso, Maximino, alcalde de Nava del Rey. Sandonís Valencia, Millán, alcalde Sieteiglesias de Trabancos. 5. Partido de Valoria la Buena: Blanco Díez, Teodomiro,

\footnotetext{
81 Todas proponen dos candidatos y a veces repiten los nombres de algunos. No formulan propuesta de candidato las siguientes entidades: Cámara de Comercio, Colegio Notarial, Asociación de Vecinos, Caja de Ahorros Provincial, Delegación de Información y Turismo, Conservatorio de Música, Granja Escuela José Antonio, Delegación de Ex combatientes, Delegación de ex cautivos, SEM.
}

82 ADGC SDG leg. 124. Circular 6/67. Valladolid, 7 de marzo de 1967. 
alcalde de Valoria la Buena. González Ruiz, José, alcalde de Amusquillo. Rivera Álvarez, Heliodoro, alcalde de Cabezón de Pisuerga. 6. Partido de Villalón de Campos: Muñoz Muñoz, Pascual, alcalde de Villalón. Pachón Vizcaíno, Procopio, alcalde de Villavicencio de los Caballeros. Sánchez Marcos, Felipe, alcalde de Mayorga de Campos.

Según todas las previsiones, nadie osó interpretar otra partitura de alcaldes sino aquella de inscritos en las ternas oficiales, aunque fuera desigual el reparto de los votos emitidos por los compromisarios.

\subsubsection{7}

\begin{tabular}{|c|c|c|c|}
\hline Emiliano Berzosa Recio $^{83}$ & & & \\
\hline Andrés Ferreras Pérez ${ }^{84}$ & Medina de Rioseco & Alcalde de Medina de Rioseco & Abogado \\
\hline Pascual Muñoz Muñoz ${ }^{85}$ & Villalón & Alcalde de Villalón & Procurador \\
\hline José María Hurtado Minguela & Olmedo $^{86}$ & Alcalde de Llano de Olmedo & Agricultor, ganadero \\
\hline Félix del Campo Esteban & Peñafiel & Alcalde de Corrales de Duero & Farmacéutico \\
\hline Francisco García Alonso & Tordesillas & Alcalde de Bercero & \\
\hline Gerardo Ureta Corcuera & Valladolid (pdo judicial) & Alcalde de Renedo Esgueva & Médico \\
\hline M Dolores Pérez Lapéña & Valladolid (ayunmto) & Concejal Ayto de Valladolid & Funcionaria \\
\hline Alfonso Acero Flórez & Org. Sindical ${ }^{87}$ & & Dir. Agencia Viajes \\
\hline Antonio Ximénez Torres & Entidades & Col. Of. Médicos & Médico \\
\hline Ignacio Sánchez López & Medina del Campo & Alcalde de Medina del Campo & Catedrático Instituto \\
\hline Manuel Rico Sevillano & Mota del Marqués & Alcalde de Casasola & Agricultor \\
\hline Máximo Pino Alonso & Nava del Rey & Alcalde de Nava del Rey & \\
\hline José González Ruiz & Valoria la Buena & Alcalde de Amusquillo & Médico \\
\hline Luis Sánchez García del Olmo ${ }^{88}$ & Organiz. Sindical & Hermd. Sindical Labradores & Empresario, ganadero \\
\hline Godofredo Garabito Gregorio & Organiz. Sindical & Sindicato Construcción & Jefe administrativo \\
\hline Luis Glez Echávarri Armendia & Entidades & Colegio Oficial DD y LL ${ }^{89}$ & Profesor $2^{\mathrm{a}}$ Enseñanza \\
\hline
\end{tabular}

83 Sustituido el 30 de enero de 1968 por José Luis MosQuERA. Le fue aceptada por el ministro de la Gobernación la dimisión presentada el 26 del mismo mes.

84 En la sesión constitutiva de la nueva Diputación.

85 Por haber sido reelegido.

${ }^{186}$ BOPVa n. ${ }^{o}$ 77, 04.04.66. Por Orden del Ministerio de Justicia queda suprimido el Juzgado de Olmedo distribuyendo sus municipios entre Valladolid y Medina del Campo, pero la representación en la Corporación provincial se mantiene.

${ }^{87}$ Convocadas las elecciones provinciales por Decreto 301/1967, en el artículo 5.1. se indica la nueva redacción del art. 227 de la Ley de Régimen Local: «Las vacantes correspondientes al grupo de representación corporativa, cuya renovación corresponde en la presente convocatoria, se dividirá en dos mitades, asignándose una de ellas a la representación de las corporaciones y entidades económicas, culturales o profesionales, y la otra mitad, a la representación de la Organización Sindical».

88 AHPva OS 125. Los votos que reciben de los compromisarios con indicación de las entidades a que pertenecen: Luis García del Olmo (COSA), 38 votos, Godofredo Garabito (Construcción) 25 votos; Marcial Rodríguez Gutiérrez (Metal), 11; Cándido VÁzQuez de Prada (COSA), 9; Celiano VÁzQuez de Prada (Transportes), 8; Juan José García García (Textil), 6; Luciano ALONSo Fuentes (Alimentación) 3; Julio Alonso MuÑoz (Alimentación) 3; Bonifacio GIMÉNEZ (Alimentación) 3; Alejandra Bujedo (Act. Sanitarias), 3; José Couto Rodríguez (Metal) 1.

89 También propuesto por el Círculo VÁzQUEZ MeLLA, ADGVA SDG leg. 124. 
El equipo provincial echa a andar desde la reunión solemne que presiden José Pérez Bustamente y Emiliano Berzosa, cuando asume la vicepresidencia el diputado-alcalde de Medina de Rioseco Andrés Ferreras ${ }^{90}$. Fuera del ritual el libro de actas hace constar «su profunda repulsa y condena por la profanación y acto vandálico cometido en el monumento de Onésimo Redondo, Caudillo de Castilla y mártir de nuestra Cruzada, que se eleve a la jefatura provincial».

Nueve meses después llega el relevo en la presidencia de la Diputación. El gobernador civil y jefe provincial del Movimiento invita el 29 de enero de 1968 a la toma de posesión, que tendrá lugar al día siguiente a las siete de la tarde, del presidente José Luis Mosquera ${ }^{91}$. Toda la ceremonia consta en un breve relato del libro de actas, que certifica la presencia con el gobernador de los señores Berzoza y Mosquera. En dicho acto el secretario general lee el escrito del ministro de la Gobernación aceptando la dimisión del anterior y agradeciéndole los servicios prestados, haciéndose constar el nombramiento para sustituirle de José Luis Mosquera, que jura el cargo ${ }^{92}$. El nuevo presidente había nacido en Madrid el año 1925, ocho años después se traslada con su familia a Valladolid donde cursa el Bachillerato y la licenciatura de Derecho. En 1967 es elegido presidente del Colegio Nacional de Agentes de Seguros y sucede a José María Luelmo en la presidencia de la Cámara Oficial de Comercio de Valladolid. Según el interesado confiesa, a pesar de sus objeciones, quedó sorprendido cuando el gobernador Pérez Bustamante le comunicó el nombramiento. No obstante, el día 29 todavía pendiente del nombramiento, cursó al ministro de la Gobernación este telegrama: «Informado por el excelentísimo señor gobernador civil de mi nombramiento de Presidente de esta Diputación, me permito insistir ante VE, lo que expuse al señor gobernador civil de que considero incompatible dicho cargo con profesión de Agente de Seguros, subdirector de "La Unión y el Fénix Español”, por lo que suplico a VE me releve de dicho nombramiento. Salúdale respetuosamente» ${ }^{93}$. Sin éxito. Permanecerá en el cargo hasta el 8 de febrero de 1976.

\footnotetext{
90 Sesión del 1 de abril de 1967, fol. 110-114.

91 AHPva OS 2977.

92 ADP Libro de Actas, sesión extraordinaria 30.01.1968, fol. 197.

93 «José Luis MosQUERA, notas biográficas» de José GonZÁLEZ ToricES en Personajes vallisoletanos, Valladolid, Diputación, 2004, 51-74.
} 


\section{CON UN AÑO DE RETRASO: LAS ELECCIONES PROVINCIALES DE 1971}

Como sucedió en los comicios municipales, se prorrogó un año el mandato de los anteriores responsables ${ }^{94}$. Al ritmo precedente se añadían nuevas cautelas. En pocas palabras, en el Ministerio de la Gobernación había preocupación por evitar cualquier desbordamiento en los posibles candidatos. Así debe interpretarse la Circular reservada ${ }^{95}$, cuyo recibo confirma el gobernador civil el 3 de febrero. Por eso, antes de publicarse la convocatoria de elecciones provinciales se hacen las siguientes consideraciones, sobre todo respecto de tres asuntos, que deben calibrarse a la hora de interpretar los resultados. Son éstos:

a) «Remoción de alcaldes: Habida cuenta de que en la mayoría de los partidos judiciales la elección de Diputado provincial suele recaer en uno de los Alcaldes del mismo, deberá tenerse en cuenta este hecho por ese Gobierno civil, con la suficiente antelación a la apertura del período electoral, a fin de llevar a cabo la renovación de aquellas Alcaldias que se estime pertinente, con objeto de que, llegado el momento de la elección, pueda contarse con los Alcaldes más idóneos para el desempeño del cargo de Diputado provincial».

b) «Designación de compromisarios: Deberán utilizarse cuantos medios se encuentren al alcance de ese Gobierno civil al objeto de garantizar al máximo la lealtad a los Principios y Leyes Fundamentales, al Caudillo y al Príncipe de España, de los compromisarios que hayan de votar a su vez en la elección».

c) «Selección de candidatos: Ha de tenerse presente que en estas elecciones provinciales la Autoridad gubernativa goza de un margen más amplio para orientar la selección de candidatos, por lo que esta facultad deberá utilizarse adecuadamente. Es importante que se mantenga un estrecho contacto con los Presidentes de las Diputaciones, a fin de utilizar su cooperación efectiva en la designación de los candidatos del tercio representación corporativa, por cuanto que es de este grupo de diputados provinciales de donde normalmente extraen sus colaboradores más inmediatos y permanentes».

\footnotetext{
94 D-L 9 de octubre 1969, (BOE, 25).

95 ADGC SDG 131. Madrid, 27.01.1971. Ministerio de la Gobernación. Director General de Política Interior. Director General de Administración Local a Gobernador Civil de la Provincia de Valladolid.
} 
Según la Circular reservada del gobernador civil $^{96}$, diez eran las plazas y correspondían al ayuntamiento de la capital, partidos judiciales de Valladolid, Nava del Rey, Villalón de Campos, Olmedo, Peñafiel, Tordesillas, dos representantes del grupo de entidades y uno de la $\mathrm{OS}^{97}$. Promulgado el Decreto de la convocatoria, retorna el itinerario acostumbrado. El Boletín provincial publica ${ }^{98}$ las circulares oportunas, junto con el calendario electoral, abierto el 26 de febrero el plazo para inscribir corporaciones y entidades (total, 59; ver Cuadro II). Un mes después, el domingo 21 de marzo, tendrá efecto la reunión extraordinaria de los ayuntamientos para elegir sus compromisarios. El consistorio de la capital votó a los suyos en el partido judicial y en nombre del ayuntamiento en dos sesiones extraordinarias consecutivas ( 21 y 22 de marzo). En la primera, fueron proclamados aquellos concejales que recibieron entre 16 y 12 votos: Francisco Bravo, Aureliano de Castro, Francisco Lesmes, Félix Tremiño, Alfredo Buiza, Francisco Fernández, Elesio Gatón, Pablo López Pinto, José Martín Elvira. Estos participarán en la elección del diputado por el partido judicial junto con los designados por los dieciséis pueblos integrantes del partido ${ }^{99}$ :

Arroyo: Pedro Pérez Villar. Ciguñuela: Juan José Llorente Cortijo. Cistérniga: Baltasar Hernando Montalvillo. Fuensaldaña: Miguel Morante Barriga. Geria: Alejandro Caso Lozano. Laguna de Duero: Pedro González Pérez. Renedo: Gerardo Ureta Corcuera. Robadillo: Julián Adalia Giralda. Santovenia: Francisco Arias Fernández. Simancas: Juan Pascual Fraile. Traspinedo: Horacio Olmedo Peña. Tudela de Duero: Vicente Alvarez Díez. Villabáñez: Félix Jesús de Fuentes Díez. Villanubla: Pompeyo Gil Lázaro. Zaratán: Mario Pinedo Chaves.

A tenor de la certificación de José Pascual Araujo, secretario general de la Diputación y de la junta provincial del censo electoral, conocemos con detalle los nombres de los candidatos y votos recibidos en cada uno de los sectores, convocados al efecto en el palacio provincial el domingo, 28 de marzo ${ }^{100}$, para incorporar diez nuevos diputados. No todos los diez diputados electos tuvieron idéntico apoyo. Así en los partidos de

\footnotetext{
${ }^{96}$ ADGC SDG 131.

97 Entre las vacantes se censa la de María Dolores PéREZ (por terminar su mandato de concejal de Valladolid), Luis GoNZÁLEZ ECHÁvARRI (fallecido en 1970), y cese de los alcaldes: (1968). Félix DEL CAMPO, (1970): Maximino PINO, PASCUAl MuÑoz.

98 BOPVa 50, 02.03.1971.

99 ADGC SDG 131.

100 ADGC SDG 131.
} 
Medina de Rioseco, Nava del Rey y Valladolid los votos se concentraron en un único candidato. Mientras que se repartieron entre tres en los partidos de Villalón y Peñafiel o entre dos candidatos en los de Olmedo y Tordesillas, con la consiguiente proclamación del más votado. Mayor dispersión en candidatos y sufragios se aprecia en el grupo de Sindica$\operatorname{tos}^{101} \mathrm{y}$ de entidades ${ }^{102}$. El mandato de algunos será más breve (tres años, hasta concluir el plazo para el que fueron elegidos sus predecesores). Idéntica operación realizaron el organismo sindical y las entidades con derecho a designar compromisarios y proponer candidatos. Aquél presentó ocho candidatos, venciendo el avalado por el sindicato de Banca $^{103}$, mientras que por las entidades resultaron elegidos los propuestos por el colegio oficial de Médicos y por los afiliados de la Guardia de Franco.

El trámite postrero era la toma de posesión de los nuevos diputados, el uno de abril, en sesión que presiden el gobernador Ibáñez Trujillo y el presidente José Luis Mosquera. Según aludimos antes, las palabras del presidente de la Diputación tenían poco parecido con el pasado, tanto en la forma de dirigirse a los diputados -«queridos compañeros y amigos»- como en el planteamiento y dinámica de la institución. Si la Diputación -son sus palabras - es y debe continuar siendo la genuina representación de la Provincia en coordinación con el Gobierno Civil, también deberá recoger las críticas para adecuar a los mejores resultados las actuaciones ${ }^{104}$. Un programa más abierto y desde luego alerta a las demandas de la opinión pública. En la sesión inaugural el diputado Ignacio Sánchez, alcalde de Medina del Campo, asume desde este día la vicepresidencia.

\footnotetext{
101 Manuel Fuentes GonzÁlez (11 votos), Marcelino Cuellar Fraile (8), José Vidal García (6), César Berrocal García (2), Marcial Rodríguez Gutiérrez (1), Bonifacio Jiménez ReneDO (1).

102 Félix Alonso Zancada (20 votos), Francisco Igea Laporta (9), Federico Sáez Vera (9), Aurelio Ramírez Gallardo (6), Jesús Parra Bustos (6), Francisco de Anta Franco (5), Santiago González García (4), Carlos Balmori lópez (4), María Camino García Abadía (4), Anastasio Cobreros Cuadrado (2), José María Campos Setien (2).

103 L 22.03.71, $3^{\mathrm{a}}$.

104 Acta de la sesión del 1 de abril de 1971, fols. 71-73.
} 


\subsubsection{1 ${ }^{105}$}

\begin{tabular}{|c|c|c|c|}
\hline José Luis Mosquera Pérez & & & Presidente \\
\hline Ignacio Sánchez López ${ }^{106}$ & Medina del Campo & Alcalde de Medina del Campo & Vicepresidente \\
\hline Manuel Fuentes Hernández $z^{107}$ & Medina de Rioseco & Alcalde de Medina de Rioseco & Industrial \\
\hline Manuel Rico Sevillano ${ }^{108}$ & Mota del Marqués & Alcalde de Casasola & Agricultor \\
\hline Basilio Sáez Hernández ${ }^{109}$ & Nava del Rey & Alcalde de Nava del Rey & Industrial \\
\hline Jesús Herrero García & Olmedo & Alcalde de Iscar & Industrial \\
\hline Francisco Sanz Olmedo & Peñafiel & Alcalde de Peñafiel & Profesor mercantil \\
\hline Félix Calvo Casasola & Tordesillas & Alcalde de Villalar Comuneros & Abogado, prof. Univ. \\
\hline José González Ruiz ${ }^{110}$ & Valoria la Buena & Alcalde de Amusquillo & Médico \\
\hline Gerardo Ureta Corcuera ${ }^{111}$ & Valladolid (p. judicial) & Alcalde de Renedo Esgueva & Vicepresidente ${ }^{112}$ \\
\hline $\mathrm{M}^{\mathrm{a}}$ Teresa Iñigo de Toro & Valladolid (ayunt $\left.^{\circ}\right)^{113}$ & Concejal Ayto de Valladolid & Directora de Emisora \\
\hline Santos Valín Cisneros ${ }^{114}$ & Villalón & Alcalde de Villalón & Veterinario \\
\hline Luis Sánchez García del Olmo & Organización Sindical & Hd Sindical Labradores & Empresario, Ganadero \\
\hline Godofredo Garabito Gregorio & Organización Sindical & Sindicato Construcción & Jefe administrativo \\
\hline Manuel Fuentes González & Organización Sindal $^{115}$ & Sindicato de Banca y Bolsa & Director de Banca \\
\hline Félix Alonso Zancada ${ }^{116}$ & Entidades & Guardia de Franco & Profesor Mercantil \\
\hline Francisco Igea Laporta & Entidades & Colegio de Médicos & Médico \\
\hline
\end{tabular}

${ }^{105}$ El calendario electoral en BOPVa n. ${ }^{\circ}$ 50, 02.03.1971. La convocatoria en el Decreto 307/71, 20 de febrero (BOE 25), indicándose que por el Decreto-Ley 17/69 se había prorrogado por un año el mandato de las diputaciones provinciales y consejeros de cabildos. Una vez concluidas las elecciones municipales, procede celebrar las provinciales.

106 Sesión de 25.02.74. Despedida de Ignacio Sánchez hasta ahora alcalde de Medina del Campo.

107 Para completar el mandato

${ }^{108}$ Reelegido.

109 Para completar el mandato.

${ }^{110}$ Reelegido.

111 Reelegido.

112 Sesión 25.02.74.

113 En su elección participan los tres compromisarios elegidos en la sesión municipal del 22.03.71: Francisco Bravo, Francisco Lesmes y J. Martín Elvira. A la semana siguiente los miembros de la Permanente felicitan a María Teresa IÑIGO por haber sido designada diputada provincial. AMV 259, 31.03.1971, fol. 40.

114 Para completar el mandato.

115 AHPva Org. Sind. 3623. 29.03.1971. El delegado provincial de la OS comunica al secretario nacional los nombres de los compromisarios y resultados en la elección de diputados provinciales en que resultó elegido Manuel FuENTES GONZÁLEZ, director del Banco de Valladolid y perteneciente a la agrupación de antiguos miembros del Frente de Juventudes. L 22.03.1971, $3^{\text {a }}$ : En estas elecciones debió de competir con los demás candidatos de representación sindical César BERROCAL, vocal del sindicato de Alimentación; Marcelino Cuellar Fraile, del sindicato de Ganadería, Tomás García Hernández, jurado de empresa del Sindicato del Metal, Luis NiETo Tovar, vocal de la Hermandad de Labradores de Corcos del Valle, Marcial Rodríguez GutiérRez, del sindicato del Metal, José VidAL GarCía del sindicato de Transportes. En otro documento con la relación de elegidos en la Diputación, fechada el 28 de marzo del mismo año, se indica la profesión de los miembros de la corporación provincial: Félix CALVO: abogado y profesor. Jesús HERRERO: industrial. Manuel FuENTES HERNÁNDEZ: industrial. Gerardo URETA: médico. María Teresa IÑIGO: directora de $L a \mathrm{Voz}$. Francisco SANZ OlmEdo: administrativo. Santos Valín: veterinario. Basilio SÁEZ: industrial. Francisco Alonso ZANCADA: profesor mercantil.

116 Libertad 26.03.1971, 2 ${ }^{\mathrm{a}}$. Además de Zancada e Igea fueron propuestos otros nombres por diferentes entidades: SEM, Alféreces Provisionales, Colegios oficiales de Ingenieros de Caminos, de 


\section{LAS ÚLTIMAS ELECCIONES DE DIPUTADOS PROVINCIALES DEL FRANQUISMO(1974)}

Estas últimas elecciones del tardofranquismo mantienen el calendario y trámites de costumbre, cuyo punto de partida será la elección de compromisarios, el día 3 de marzo. Por los ayuntamientos concurrirán una semana después al palacio provincial los elegidos en el plenario municipal ${ }^{117}$.

Del bloque de candidatos que ahora aportan las 65 entidades registradas (a veces un mismo candidato recibe el padrinazgo de varias entidades $)^{118}$, el gobernador selecciona y proclama las candidaturas oficiales sobre las que deberán pronunciarse los compromisarios. Todos los agraciados tomarán posesión el 1 del mes siguiente en el curso de la sesión extraordinaria convocada con este fin ${ }^{119}$ y presidida por el gobernador Ibáñez Trujillo y el presidente Mosquera, ratificándose el nombramiento de los nuevos diputados provinciales que certifica el acta de la junta electoral del 10 de marzo. Tras jurar el cargo, el presidente entrega las insignias y queda constituida la corporación al completo. Seguidamente María Teresa Iñigo, que con los demás diputados cesantes, por pérdida de su condición representativa, habían sido invitada al acto, pronunció un elocuente discurso de despedida (es la única cita textual del acta) y Félix Gómez Navas lo hace en nombre de los nuevos. Acto seguido, el presidente designa vicepresidente a Gerardo Ureta, confirmándole en el cargo que venía desempeñando.

Previamente, y por primera vez, las actas provinciales anticipan la noticia de la nueva corporación ${ }^{120}$ e incluso introducen como novedad la asis-

\footnotetext{
Gestores Administrativos, de Arquitectos (Carlos BALMORI), Ateneo (José M. CAMPOS), Abogados (Jesús PARRA), Ingenieros Agrónomos (SÁez Vera), Asociación de la Prensa (Francisco DE ANTA), SEPEM (Camino Abadía).

117 AMV 273, 03.03.74, fol. 101 ss.

118 AMV 273. Elegidos en la sesión extraordinaria del 3 de marzo que preside el alcalde accidental Francisco FERNÁNDEZ SANTAMARÍA. En primer lugar, se lee el Oficio del gobernador referido al Decreto 178/1974, por el que se convocan elecciones provinciales el día 10 para la renovación trienal de la Diputación Provincial. En votación secreta resultan elegidos compromisarios: Aureliano Castro (10 votos), Luis Chulilla (9), Gonzalo Alonso (9), Miguel Martín LuQuero (8), Jesús de Vicente (8), José María Muñoz (7), Francisco Fernández Santamaría (1), Francisco Bravo Revuelta (1). Sin mencionar los votos obtenidos se designa para elegir representante de este Ayuntamiento a Aureliano CASTRO, Luis ChUliLla y Gonzalo Alonso.

119 BOPVa 28 de marzo. L 01.04.74 Hoy han tomado posesión. L 02.04 continúa la información precedente.

${ }^{120}$ Es en la sesión ordinaria del 11 de marzo, fol. 45. El presidente Mosquera informa sobre la elección de nuevos diputados celebrada ayer para renovar la corporación y cuya posesión se efectuará
} 
tencia de los electos a la sesión extraordinaria antes de tomar posesión de los cargos. En concreto, se trata de la sesión del 25 de marzo, en la que, después de aprobarse el acta de la última sesión, «el presidente dedica unas palabras de salutación y bienvenida a los nuevos diputados electos que, como público e invitados expresamente para este acto asisten a la sesión; el señor Mosquera expresa su satisfacción por verles presentes, y considera que esos primeros contactos previos a la posesión oficial sirvan para que vayan tomando contacto directo de los asuntos de la casa» ${ }^{121}$.

\subsubsection{4}

\begin{tabular}{|l|l|l|l|}
\hline José Luis Mosquera Pérez & & & Presidente \\
\hline Gerardo Ureta Corcuera & Valladolid (pdo jud) & Alcalde Renedo de Esgueva & Vicepresidente \\
\hline Juan Antonio Cendón Tadeo & Medina del Campo & Alcalde Medina del Campo & \\
\hline Manuel Fuentes Hernández ${ }^{122}$ & Medina de Rioseco & Alcalde Medina de Rioseco & Industrial \\
\hline Manuel Martín Díez & Mota del Marqués & Alcalde de Mota del Marqués & \\
\hline Basilio Sáez Hernández & Nava del Rey & Alcalde de Nava del Rey & Industrial \\
\hline Antonio Morán García & Peñafiel & Alcalde de Peñafiel & \\
\hline Justo Agudo López & Valoria la Buena & Alcalde de Cubillas Sta Marta & \\
\hline Félix Gómez Navas & Villalón de Campos & Alcalde de Villalón de Campos & \\
\hline Nicolás Montero Quiroga & Valladolid (ayunt $\left.{ }^{\circ}\right)$ & Concejal Ayto de Valladolid & \\
\hline Félix Calvo Casasola & Tordesillas & Alcalde Villalar Comuneros & Abogado. Profesor \\
\hline Jesús Herrero García & Olmedo & Alcalde de Iscar & Industrial \\
\hline Miguel Molero Sanpedro & Entidades & Colegio de Abogados & Abogado \\
\hline Isidoro González Gallego & Entidades & Colegio Of.Docts y Licends ${ }^{124}$ & Agregado de Instituto \\
\hline Félix Alonso Zancada & Entidades & Guardia de Franco & Profesor Mercantil \\
\hline Luis Sanjosé Calvo & Organización Sindical & & \\
\hline Manuel Fuentes González & Organización Sindical & & Director de Banca \\
\hline
\end{tabular}

\section{LA RENOVACIÓN PARCIAL DE 1976}

A escasas fechas de finalizar la dictadura y comenzar la transición democrática, de conformidad con la Ley $41 / 75^{125}$, desde el ministerio de la Gobernación recién estrenado por José García Hernández se dictan las primeras disposiciones. En concreto, la elección en su totalidad de presidentes de las diputaciones, excluida la de Navarra, presidentes de cabil-

el próximo uno de abril. Son once. Se expresa la felicitación a todos y especialmente a FuENTES y SÁEZ, que han sido reelegidos.

121 Sesión 15.03 .74 , fol. 56v.

122 Condecorado con la Cruz de Caballero de Cisneros en la conmemoración del cuadragésimo aniversario del 4 de Marzo. L. 04.03.1974, $5^{\mathrm{a}}$.

123 También propuesto por Antiguos Miembros del Frente de Juventudes.

124 También propuesto por el colectivo de Agregados de Instituto.

125 De 19 de noviembre de 1975, que aprueba las Bases del Estatuto de Régimen Local, en su disposición transitoria $1^{\mathrm{a}}$ prevé celebrar dentro de cuatro meses las elecciones de alcaldes, presidentes de cabildos y de diputaciones provinciales. 
dos insulares y de alcaldes de las capitales de provincia y de poblaciones mayores de cien mil habitantes, salvo Madrid y Barcelona, así como la mitad de los municipios restantes, según la antigüedad de su titulares ${ }^{126}$. Entre las modificaciones que se introducen en la normativa precedente y requisitos para ser proclamados candidatos destacan los siguientes: vecindad en el municipio, solicitud por escrito a la Junta Electoral del censo, ser o haber sido presidente de la diputación o alcalde o concejal de la respectiva corporación, ser propuesto por vecinos en número no inferior a mil o al 1\% del total de electores, en el caso de alcaldes, o del $0,5 \%$ en los presidentes de diputación. También podían ser propuestos por cuatro consejeros del consejo local o provincial del Movimiento, o bien por una asociación política, conforme a lo dispuesto en el Decreto 1970/75. No sería precisa realizar la elección en caso de optar un único candidato. Tanto el presidente de la corporación provincial como el alcalde serán elegidos por los diputados o concejales, debiendo expirar sus mandatos al producirse la segunda renovación de sus corporaciones. Por último, las elecciones de presidentes debían celebrarse el 11 de enero y la toma de posesión el 8 de febrero (art. 9). Un cambio de última hora, que se justifica «para garantizar la máxima independencia de los miembros de las corporaciones locales en el momento de emitir sus votos para la designación de los presidentes de las mismas», retrasa la elección de presidentes al 18 de enero y al 25 las de alcaldes, ampliando hasta once días antes de celebrarse las solicitudes para ser proclamados candidatos ${ }^{127}$.

Según anuncia el diario oficial de la provincia, José Luis Mosquera convocó a los diputados el 8 de febrero para dar posesión al presidente electo de la Diputación Provincial Fernando Velasco Andrés. En el curso de la sesión extraordinaria, que preside el gobernador civil y asiste la Diputación en pleno, el nuevo titular recibe el bastón de mando y la medalla de la corporación provincial. Con esta ceremonia se había cumplido la renovación en la presidencia. Dos meses después acceden a la corporación dos nuevos diputados elegidos en la convocatoria celebrada el 28 de marzo del mismo año. Dicha convocatoria trataba de cubrir las vacantes existentes por cualquier causa (por no haber sido reelegidos o cesados los alcaldes o los representantes de corpora-

\footnotetext{
126 BOP n. ${ }^{\circ}$ 281, 13 diciembre de 1975. Ministerio de la Gobernación Decreto 3230/75, de 5 de diciembre, por el que se convocan elecciones para proveer los cargos (...) conforme al nuevo Estatuto de Régimen Local. En la página 3 del mismo BOP el gobernador civil publica la relación de los 114 alcaldes pendientes de renovación con la antigüedad de sus titulares en el cargo. Inicia la relación el alcalde de Matilla de los Caños, ejerciente desde 1943, seguido por los de San Vicente del Palacio (1945) y Santervás (1948); la renovación afecta hasta el alcalde de Velascárcela, que había tomado posesión el 3 de enero de 1968.

${ }^{127}$ BOP n. ${ }^{\circ} 294,30.12 .75$. Ministerio de la Gobernación. Decreto 3411/75 de 26 de diciembre que modifica el $D^{\circ} 3230 / 75$.
} 
ciones $)^{128}$. En el caso vallisoletano estaban vacantes los puestos de diputados representantes del partido de Olmedo y de las corporaciones. El primero, con un mandato breve hasta la primera renovación trienal (abril de 1977), «por ser dicho periodo el que faltaba al anterior titular cesado por haber perdido la condición de alcalde», y el segundo, hasta la segunda renovación (abril de 1980) que faltaba al anterior, cesado al perder su condición de vecino. Con la debida antelación, el gobernador publica la relación de setenta corporaciones y entidades reconocidas para tomar parte en las elecciones provinciales ${ }^{129}$. El Archivo de la Diputación conserva el documento acreditativo de los veinticinco candidatos propuestos para la representación corporativa. Casi la mitad son docentes en diversos niveles, seguidos de abogados, médicos, y otras profesiones liberales ${ }^{130}$. Por este grupo ${ }^{131}$, resultó elegido Daniel Pato Movilla, pertenecía al gremio profesoral y que había sido propuesto por el Departamento de Seminarios y la Asociación de Cabezas de Familia. Junto con el alcalde de Olmedo José Antonio González Caviedes ${ }^{132}$ cierra el proceso y queda constituida la nueva Diputación Provincial en la sesión extraordinaria que el 1 de abril de 1976 preside el gobernador José Estévez Méndez.

Sobre lo dicho en las páginas y cuadros anteriores, una vez finalizado el recorrido y resultados de las convocatorias, cabe resaltar otros aspectos, sin necesidad de reiterar que todo el proceso se inscribe en el plan hermético del régimen. Varía la distribución en las candidaturas respecto de los comicios municipales que, como es sabido, responde al sistema de tercios de cabezas de familia, sindicales y entidades.

Como sucede en las alcaldías de las villas importantes y del ayuntamiento capitalino, los presidentes de la corporación provincial son nombrados por el ministro de la Gobernación. Desde 1944 a 1976, en esta provincia tres presidentes dirigen la corporación provincial, propuestos por el

${ }^{128}$ BOP n. ${ }^{\circ} 50,01.03 .76$ y n. ${ }^{\circ} 60,12.03 .76$.

129 A las censadas en elecciones precedentes se añaden algunas nuevas como el Círculo Cultural Onésimo Redondo (Santiago, 26), Agrupación de Jóvenes Trabajadores de Valladolid (San Blas, 6), Organización Universitaria de Estudiantes (Claudio MoYANO, 4).

130 ADP caja I -4629, exped. 4.

131 Participaron sesenta y cinco de los setenta compromisarios designados. Recibieron votos: Ramón Velasco (2), Tomás Ga De la Santa (1), Pedro Zuloaga (1), Manuel Alvarez (1), José Ma Quemada (1), Félix Campo (1), Jesús Sesmero (2), Manuel Giralda (2), Adolfo Sánchez Martín (7), Ramón Burrieza (1), Indalecio Hurtado (1), Daniel Pato (22), votos en blanco: 3.

132 En la elección participan treinta y un compromisarios de los municipios del partido, González Caviedes recibe 23 votos y José María LlORENTE GuTIÉRREZ, ocho. 
gobernador civil, quien nunca se olvidará de recordar su categoría de presidente nato de la institución, ni tampoco de exigir fidelidad y lealtad al régimen en todos los diputados, que expresan públicamente bajo juramento al posesionarse del cargo. Sin embargo, el falangismo tan expreso en las primeras corporaciones, irá decayendo paulatinamente conforme nos aceramos a la etapa del tardofranquismo.

Uno de los factores a tener presente es la permanencia o estabilidad de los diputados en el cargo. El Cuadro I del anexo aclara el ritmo de los cambios en el sector de representantes municipales por los partidos judiciales. Predomina la permanencia durante un sexenio, siendo pocas las reelecciones de diputados, aunque en ocasiones continúen como diputados aquellos elegidos hasta concluir el sexenio de sus predecesores. Destaca la estabilidad en el partido de Valladolid, representado en todo el periodo exclusivamente por los alcaldes de Tudela de Duero y Renedo de Esgueva. Idéntica estabilidad acompaña a los alcaldes de cabecera del partido (Medina del Campo, Medina de Rioseco, que siempre fueron elegidos diputados) No sucede así con los diputados representantes de los otros partidos judiciales, que deberán compartir la representación con alcaldes de otras poblaciones. Son varios los casos: Mota del Marqués (Tiedra, Ureña, Casasola), Nava del Rey (Alaejos, Sieteiglesias), Valoria la Buena (Canillas, Cabezón, Villanueva, Amusquillo, Encinas de Esgueva), Olmedo (Íscar, Llano de Olmedo). Por el partido de Tordesillas serán diputados tres alcaldes, el de la cabeza del partido y los titulares de Bercero y Villalar de los Comuneros, destacando una mayor estabilidad debido a que Calvo Casaola repite como diputado. Con todo, el record de presencia en la Diputación pertenece al presidente Emiliano Berzosa. A distancia, desde luego, de la perennidad que se observa, por ejemplo, en la Diputación de Barcelona (diputados Manuel Jaumar y Antonio Ferrer), quedan los diputados Gerardo Ureta y Félix Calvo. Si analizamos en este mismo bloque municipal la categoría de alcalde en la mayoría de los diputados elegidos, el ayuntamiento de la capital estará representado por uno de sus concejales y, por lo común, durante un sexenio. Esta aportación del municipio capitalino introduce como novedad la presencia femenina ${ }^{133}$, por vez primera en la corporación provincial y poco antes en su Ayuntamiento. Circunstancia inédita tanto en los representantes de los partidos judiciales como por las corporaciones y entidades.

En tres partidos persiste la continuidad de familias o de captación familiar de cargos municipales y provinciales que, tras ocupar puestos de dipu-

\footnotetext{
133 En la Diputación de Barcelona, recordará C. Molinero: La primera mujer que accede a la Diputación se produce en las elecciones de 1974 al ser elegida Mèrce CARBÓ, la «mamá del millón». O.c., p.
} 
tados provinciales vuelven, a la institución en la época franquista. Nos referimos, en concreto, a los apellidos Gordaliza ${ }^{134}$ en el partido de Villalón, Amigo Torres ${ }^{135}$ en el de Rioseco, y Martín Sanmartín ${ }^{136}$ en el de Olmedo.

Asimismo, la lista de candidatos de entidades y corporaciones revela que, en varios casos, hay un trasvase de aspirantes a la Diputación que, antes o simultáneamente, lo fueron al Ayuntamiento de la capital.

\section{ANEXO}

\section{CUADRO I}

\section{DIPUTADOS REPRESENTANTES POR MUNICIPIOS DE LOS PARTIDOS JUDICIALES}

\begin{tabular}{|c|c|c|c|c|c|c|c|c|c|}
\hline MEDINA DEL CAMPO & 1949 & 1952 & 1955 & 1958 & 1961 & 1964 & 1967 & 1971 & 1974 \\
\hline A. Rojo, alc. Medina Campo & ---- & ----- & ---- & & & & & & \\
\hline J.B.GäMellado, alc. Medina Cp & & & & - - & ------ & & & & \\
\hline A. Coca, alc. Medina Campo & & & & & & ------ & & & \\
\hline I. Sánchez, alc. Medina Campo & & & & & & & $\begin{array}{ll}---- \\
\end{array}$ & ------ & \\
\hline J.A. Centón, alc. Medina Cpo & & & & & & & & & ----- \\
\hline \multicolumn{10}{|l|}{ MEDINA DE RIOSECO } \\
\hline J. Amigo, alcalde Medina Ríos. & ----- & $\begin{array}{l}----- \\
\end{array}$ & & & & & & & \\
\hline R. Herrero, alc. Medina Riosec & & & ----- & ----- & & & & & \\
\hline F. Rueda, alc. Medina Riosec & & & & & ------ & ----- & & & \\
\hline A. Ferreras, alc. Medina Riosc & & & & & & & $\begin{array}{ll}----- \\
\end{array}$ & & \\
\hline M. Fuentes, alc. Medina Riosc & & & & & & & & ----- & ----- \\
\hline \multicolumn{10}{|l|}{ PEÑAFIEL } \\
\hline M. Martínez, alcalde Peñafiel & $-\overline{----}$ & & & & & & & & \\
\hline V. Lerma, alc. Peñafiel & & ------ & ------ & & & & & & \\
\hline A. Escribano, alc. Peñafiel & & & & ----- & ------ & & & & \\
\hline F. del Campo, alc. Corrales & & & & & & ------ & $\begin{array}{l}------ \\
\end{array}$ & & \\
\hline F. Sanz, alc. Peñafiel & & & & & & & & $\begin{array}{ll}----- \\
\end{array}$ & \\
\hline A. Morán, alc. Peñafiel & & & & & & & & & ------ \\
\hline
\end{tabular}

134 Eleuterio GordalizA, alcalde gamacista de Villalón en 1900, Dámaso Gordaliza GarZón, abogado de Villalón, y miembro de esta influyente familia. Vide: H. PASTRANA, La Diputación.... p. 436.

135 Félix Amigo TorRes, abogado y agricultor, representa durante la Dictadura de Primo de Rivera al distrito Rioseco-Villalón. H. Pastrana, o.c. 455.

136 Manuel MARTín SANMARTín era diputado provincial en 1926, cesa en 1929 al ser nombrado alcalde de Olmedo. Loc. cit. 460. Dejará de pertenecer a la Diputación en 1952, a la edad de 64 años. 
LAS ELECCIONES DE DIPUTADOS PROVINCIALES EN EL FRANQUISMO...

\begin{tabular}{|c|c|c|c|c|c|c|c|c|c|}
\hline MOTA DEL MARQUÉS & & & & & & & & & \\
\hline F. Moretón, alcalde de Tiedra & ----- & ------- & & & & & & & \\
\hline R. Izquierdo, alc. de Barruelo & & & ------ & & & & & & \\
\hline A. Pérez M, alc Urueña & & & & ----- & & & & & \\
\hline M. Meléndez, alc. Mota Marqs & & & & & ------ & ------ & & & \\
\hline M. Rico, alc. Casasola & & & & & & & ------ & $\begin{array}{l}----- \\
\end{array}$ & \\
\hline M. Martín, alc. Mota Marqués & & & & & & & & & -ב--- \\
\hline VALORIA LA BUENA & & & & & & & & & \\
\hline T. Martín, alcalde de Canillas & ----- & ------- & & & & & & & \\
\hline S. García, alc. de Cabezón & & & ------ & & & & & & \\
\hline J. Martínez, alc. Villanueva & & & & $\overline{-----}$ & & & & & \\
\hline A. Martín, alc. Encinas & & & & & ------- & ------ & & & \\
\hline J. Glez Ruiz, alc. Amusquillo & & & & & & & ----- & ----- & \\
\hline J. Agudo, alc. Cubillas & & & & & & & & & ------ \\
\hline NAVA DEL REY & & & & & & & & & \\
\hline D. Vadillo, alcalde Alaejos & ----- & ------ & & & & & & & \\
\hline A. García, alc. Nava del Rey & & & ------ & & & & & & \\
\hline C. Muñumer, alc. Sieteiglesia & & & & ------ & & & & & \\
\hline P. Abad, alc. de Alaejos & & & & & ------ & ------ & & & \\
\hline M. Pino, alc. Nava del Rey & & & & & & & ------ & & \\
\hline B. Sáez, alc. Nava del Rey & & & & & & & & $\begin{array}{ll}----- \\
\end{array}$ & ------ \\
\hline OLMEDO & & & & & & & & & \\
\hline M. Martínez, alc. Olmedo & ----- & & & & & & & & \\
\hline F. Santiago, alc. Olmedo & & ------ & ------ & & & & & & \\
\hline E. Valero, alc. Olmedo & & & & ------ & -------- & & & & \\
\hline J.M. Hurtado, alc.Llano Olmd & & & & & & ------ & $\begin{array}{c}----- \\
\end{array}$ & & \\
\hline J. Herrero, alc. Iscar & & & & & & & & ----- & $-\overline{----}$ \\
\hline VILLALÓN & & & & & & & & & \\
\hline T. Gordaliza,alc. Villalón & ------ & ------ & & & & & & & \\
\hline A. Pardo, alc. Fontihoyuelo & & & ------- & ------ & & & & & \\
\hline P. Muñoz, alc. Villalón & & & & & ------- & -------- & ------ & & \\
\hline S. Valin, alc. Villalón & & & & & & & & ------ & \\
\hline F. Gómez, alc. Villalón & & & & & & & & & $-\overline{---}$ \\
\hline TORDESILLAS & & & & & & & & & \\
\hline M. de Paz, alcalde Tordesills & --.--- & ------- & ------ & & & & & & \\
\hline F. Calvo, alc. Villallar Comunrs & & & & ----- & ------- & & & ----- & ----- \\
\hline F.García, alc. de Bercero & & & & & & $\overline{-------}$ & 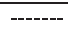 & & \\
\hline VALLADOLID & & & & & & & & & \\
\hline M. Martín, alcalde Tudela $D^{\circ}$ & --.-- & ------- & ----- & & & & & & \\
\hline J.M.G ${ }^{\text {a }}$ Gutierrez, alc. Renedo & & & & ----- & ------- & & & & \\
\hline G. Ureta, alc. Renedo & & & & & & ------- & $\begin{array}{c}------- \\
-1\end{array}$ & ------ & ------ \\
\hline
\end{tabular}




\author{
CUADRO II
}

\title{
RELACIÓN DE CORPORACIONES Y ENTIDADES INSCRITAS EN EL REGISTRO DEL GOBIERNO CIVIL A LAS QUE SE RECONOCE EL DERECHO A TOMAR PARTE EN LAS ELECCIONES PROVINCIALES CONVOCADAS POR DECRETO DE 20 DE FEBRERO DE $1971^{137}$
}

\begin{tabular}{|c|c|}
\hline NOMBRE & DOMICILIO \\
\hline Universidad & Plaza de la Universidad \\
\hline Real Academia de Bellas Artes & Casa de Cervantes \\
\hline Real Academia de Medicina y Cirugía & Universidad \\
\hline Instituto Nacional de Enseñanza «Zorrilla» & Plaza de San Pablo \\
\hline Instituto Nacional de Enseñanza «Núñez de Arce» & Paseo Isabel la Católica \\
\hline Instituto de Enseñanza Laboral & Medina del Campo \\
\hline Escuela de Comercio & Estación, 5 \\
\hline Escuela Normal del Magisterio & Plaza de España, 8 \\
\hline Escuela de Ingenieros Técnicos Industriales & Merced, 8 \\
\hline Escuela de Formación Profesional «Onésimo Rdo» & Carretera de Segovia \\
\hline Escuela de Maestría Industrial & Merced, 8 \\
\hline Colegio Provincial de Abogados & Audiencia, c/ Angustias \\
\hline Colegio Notarial & Teresa Gil, 14 \\
\hline Colegio de Procuradores & Audiencia, c/ Angustias \\
\hline Colegio Oficial de Médicos & Pasión, 13 \\
\hline Colegio Oficial de Farmacéuticos & Claudio Moyano, 24 \\
\hline Colegio Oficial de Odontólogos & Santiago, 25 \\
\hline Colegio Provincial de Veterinarios & Castelar, 3 \\
\hline Colegio Oficial de Arquitectos & Santiago, 25 \\
\hline Colegio Oficial de Aparejadores & Santiago, 25 \\
\hline Colegio de Ingenieros Industriales & Veinte de Febrero, 2 \\
\hline Colegio Nacional de Peritos Industriales & Divina Pastora, 1 \\
\hline Colegio Oficial de Doctores y Licenciados & Santiago, 26 \\
\hline Colegio provincial de Auxiliares Sanitarios & Salvador, 16 \\
\hline Colegio Oficial de Peritos Industriales & Plaza de Madrid, 4 \\
\hline Colegio Oficial de Corredores de Comercio & Gamazo, 3 \\
\hline Colegio Oficial de Agentes Comerciales & Colmenares, 1 \\
\hline Colegio Oficial de Titulares Mercantiles & Estación, 5 \\
\hline Colegio Oficial de Gestores Administrativos & Santiago, 25 \\
\hline Colegio Oficial de la Propiedad Urbana & Filipinos, 5 \\
\hline Cámara Oficial Sindical Agraria & Dos de Mayo, 5 \\
\hline Cámara Oficial de Comercio e Industria & General Mola, 10 \\
\hline Colegio Oficial de Ingenieros Agrónomos & Claudio Moyano, 24 \\
\hline Colegio Oficial de Agentes Propied. Inmobiliaria & Divina Pastora, 1 \\
\hline Asociación de Vecinos & Santa María 7 y 9 \\
\hline Caja de Ahorros Provincial & Plaza de España s/n \\
\hline Ateneo de Valladolid & Plaza de España, 10 \\
\hline Conservatorio de Música & Zúñiga, 23 \\
\hline Delegación Provincial Ministerio de I y T & Paseo de Zorrilla, 48 \\
\hline Departamento Provincial de Seminarios & Santiago, 26 \\
\hline Guardia de Franco & Santiago, 26 \\
\hline Granja Escuela «José Antonio» & Diputación, c/ Angustias \\
\hline Asociación de la Prensa & Plaza España, 10 \\
\hline Delegación Provincial de Excombatientes & Santiago, 26 \\
\hline Delegación Provincial de Excautivos & Santiago, 26 \\
\hline Sindicato Español Universitario & Gamazo, 7 \\
\hline
\end{tabular}

137 ADGC SDG 131. Firmada el 8 de marzo de 1971 por el gobernador civil Alberto IBÁÑEZ TRUJILLO. 
LAS ELECCIONES DE DIPUTADOS PROVINCIALES EN EL FRANQUISMO...

\begin{tabular}{|c|c|}
\hline Delegación Provincial Ministerio de I y T & Paseo de Zorrilla, 48 \\
\hline Departamento Provincial de Seminarios & Santiago, 26 \\
\hline Guardia de Franco & Santiago, 26 \\
\hline Granja Escuela «José Antonio» & Diputación, c/ Angustias \\
\hline Asociación de la Prensa & Plaza España, 10 \\
\hline Delegación Provincial de Excombatientes & Santiago, 26 \\
\hline Delegación Provincial de Excautivos & Santiago, 26 \\
\hline Sindicato Español Universitario & Gamazo, 7 \\
\hline Servicio español del Magisterio & Santiago, 26 \\
\hline Servicio Español Profesorado Enseñanza Media & Santiago, 26 \\
\hline Servicio Español Profesorado Enseñanza Técnica & Santiago, 26 \\
\hline Servicio Español Profesorado Enseñanza Superior & Santiago, 26 \\
\hline Asociación Profesores Adjunto Univd de Valladolid & Plaza de la Universidad \\
\hline Asociación Profesores Adjuntos Inst ${ }^{\circ}$ Ens. Media & Instituto «Zorrilla”, Plaza de San Pablo \\
\hline Asociación de Cabezas de Familia & Santiago, 26 \\
\hline Unión Territorial Cooperativas del Campo & Claudio Moyano, 26 \\
\hline Caja Rural Provincial de Valladolid & Claudio Moyano, 26 \\
\hline Círculo Cultural «Juan Vázquez de Mella» & Librería, 11 \\
\hline Agrupación Antiguos Miembros Frente Juventudes & Santiago, 26 \\
\hline Hermandad Provincial Alféreces Provisionales & Veinte de Febrero, 2 \\
\hline Colegio Oficial de Ingenieros de Caminos & Menéndez Pelayo, 2 \\
\hline & \\
\hline
\end{tabular}

